\title{
THE CONSEQUENCES OF GLOBAL WARMING DUE TO ICE- ALBEDO FEEDBACK AND GREENHOUSE EFFECT IN AN ENERGY BALANCE DAISYWORLD MODEL
}

\author{
RUEANGPHANKUn, T. ${ }^{1}-$ SUKAWAT, D. ${ }^{2}-$ YOMSATIEANKUL, W..$^{*}$ \\ ${ }^{I}$ Department of Mathematics, Faculty of Science, \\ King Mongkut's University of Technology Thonburi (KMUTT) \\ 126 Pracha Uthit Road, Bang Mod, Thung Khru, Bangkok 10140, Thailand \\ ${ }^{2}$ The Joint Graduate School of Energy and Environment, \\ King Mongkut's University of Technology Thonburi (KMUTT) \\ 126 Pracha Uthit Road, Bang Mod, Thung Khru, Bangkok 10140, Thailand \\ *Corresponding author \\ e-mail: warisa.yom@mail.kmutt.ac.th \\ (Received $16^{\text {th }}$ Nov 2017; accepted $27^{\text {th }}$ Feb 2018)
}

\begin{abstract}
The detrimental effects of global warming on vegetation have been mathematically modelled with the application of Daisyworld. Daisyworld models explain the interaction between life and the physical environment. Daisyworld helps to describe the adaptive mechanisms for two plant species of daisy populations; namely black and white daisies. An environmental condition that affects the daisy growth rate is the Earth's surface temperature. This study aims to modify the Daisyworld equations by incorporating global warming factors into the model. The factors include ice-albedo feedback and greenhouse gases. Three different scenarios are examined, the ice-albedo feedback, greenhouse gases and a combination of ice-albedo feedback and greenhouse gases. In addition, greenhouse gases are considered with the differentiations of $\mathrm{CO}_{2}$. The numerical results compare the relationship between the planet temperature and fractional area of black and white daisies on the Earth's surface among the three scenarios. Under the scenario of applying both ice-albedo feedback and greenhouse gases, the results illustrate that as the Earth's average temperature increases, the plant species become more vulnerable to extinction.
\end{abstract}

Keywords: Daisyworld, global warming, ice-albedo feedback, greenhouse gases, $\mathrm{CO}_{2}$, daisy extinction, planet temperature

\section{Introduction}

The current state of the Earth's climate has changed dramatically because of global warming (Viola, 2010). Global warming refers to the increase of temperature of the Earth, having adverse effects on both societies and the ecosystem. The main cause of this phenomenon is human induced. Especially the release of greenhouse gases into the atmosphere through the burning of fossil fuels such as coal, oil and natural gas for energy production. This, coupled with large-scale deforestation, creates the greenhouse effect. Greenhouse gases absorb heat energy reflected from the Earth back into the atmosphere storing some heat within the Earth's atmosphere. The major greenhouse gases are water vapour, carbon dioxide $\left(\mathrm{CO}_{2}\right)$, methane $\left(\mathrm{CH}_{4}\right)$, nitrous oxide $\left(\mathrm{N}_{2} \mathrm{O}\right)$, chlorofluorocarbons ( $\left.\mathrm{CFCs}\right)$, and sulfur hexafluoride $\left(\mathrm{SF}_{6}\right)$. These gases originate from processes conducted at industrial factories, electrical industry and the transportation sector. The effect of global warming leads to the melting of icebergs, rising sea level and more frequent/violent meteorological events (Viola, 2010; Wang and Chameides, 2005). 
As mentioned above, greenhouse gases are influential factors on global warming. Of the many different greenhouse gases, a large focus has been placed on $\mathrm{CO}_{2}$. Since the industrial revolution, the amount of $\mathrm{CO}_{2}$ in the atmosphere has significantly increased (NOAA Climate.gov, 2017). An extensive amount of fossil fuels has been burned each decade following the industrial revolution. The overall affect is copious amounts of $\mathrm{CO}_{2}$ being released into the Earth's atmosphere. Before the industrial revolution, the atmospheric concentration of $\mathrm{CO}_{2}$ was about $280 \mathrm{ppm}$. When a continual observation began at Mauna Loa in 1958, $\mathrm{CO}_{2}$ concentration was roughly $316 \mathrm{ppm}$. In 2013, the daily average concentration of $\mathrm{CO}_{2}$ measured at Mauna Loa surpassed $400 \mathrm{ppm}$. Since then, the monthly average of carbon dioxide levels has periodically exceeded $400 \mathrm{ppm}$, as shown in Figure 1 (NOAA Climate.gov, 2017).

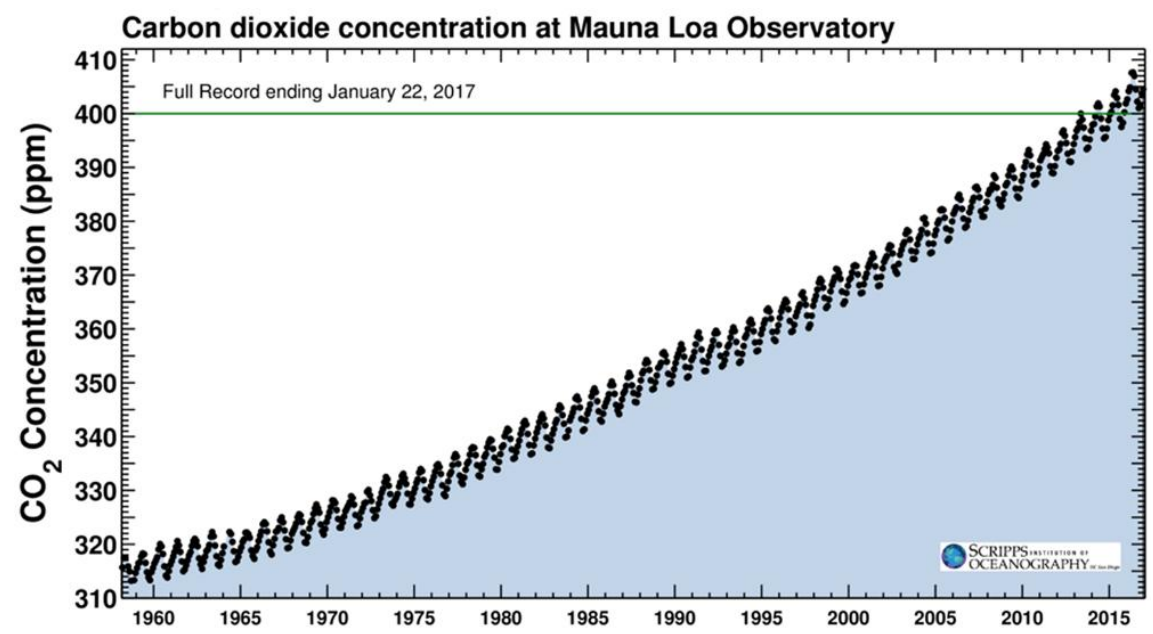

Figure 1. Concentrations of carbon dioxide in Earth's atmosphere have risen rapidly since measurements began nearly 60 years ago, climbing from 316 parts per million (ppm) in 1958 to more than 400 ppm today. SCRIPPS INSTITUTION OF OCEANOGRAPHY (Jones, 2017)

Furthermore, another factor which affects the global temperature change is icealbedo feedback. The factor describes the climatic process of changing ice coverage. The occurrence of this phenomenon is due to ice having a higher albedo than either land or water surfaces. This means that it reflects more of the solar radiation, lessens the effect caused by surface warming, refrigerates the surface temperature and induces the formation of ice. Hence, as global ice cover decreases due to ice melting, the reflectivity of Earth's surface decreases accordingly. The more incoming solar radiation absorbed by the surface, the more the surface temperature increases, causing ice to melt and escalating the average temperature of the Earth (Mcgehee and Widiasih, 2012).

Global warming attributes to the rise of the average temperature of the Earth's atmosphere through many factors (Viola, 2010; Wang and Chameides, 2005). Using the mathematical model Daisyworld, factors ascribed to the global warming phenomenon can be studied within a planetary system. This model is a tool in describing and analyzing the fundamental processes of the global climate and terrestrial biosphere. A zero-dimensional Daisyworld model (known as the original model) was presented by Watson and Lovelock in 1983. The model proposes that the planet behaves as a selfregulating super-organism, in which the biotic and abiotic environment interact and adapt to potential changes to continue their existence (Barnsley, 2007; Dyke, 2008). 
Watson and Lovelock first presented Daisyworld in 1983 as an imaginary planet illuminated by the distant sun. The imaginary planet size is defined to represent the size of Earth. The atmospheric greenhouse gases are assumed to remain constant; therefore, the greenhouse effect of the planet does not change. The results have summarized that the planet is warmed by radiation from the sun. Moreover, it has been described as a consequence of life in a changing environment on the planet, concluding that the environment is related to life. Hence, life and environment are studied as two components in a coupled system. The environment is expressed by the global and local temperature of the planet. In which temperature depends on the albedo of the planet surface and the amount of incident luminosity from the sun. The albedo is the fraction of the solar radiation which reflects from the surface of the planet back to space. While the solar luminosity is the total output power of the sun radiating back to space. The changing of solar luminosity acts as an external factor in the Daisyworld model. In this regard, life is represented by two inhabitants of daisy population, consisting of the black and the white daisy. The black daisies reflect less light but absorb more solar radiation than the bare ground. In contrast, the white daisies reflect lighter but absorb less solar radiation than the bare ground. The growth rate of the black and white daisies depends on local temperature. The Daisyworld model also covers bare ground (Barnsley, 2007; Watson and Lovelock, 1983; Adams et al., 2003).

There are several studies that have researched the extensions of the zero-dimensional Daisyworld model by Watson and Lovelock (1983). Saunders (1994) shows how regulation can arise without natural selection through the application of the Daisyworld model. Lenton and Lovelock (2000) suggested that constraints on adaptation are an important part of a self-regulating planetary system. Cohen and Rich (2000) introduced interspecific competition into the growth equations of Daisyworld, which explains the interaction between the daisy populations. Boyle et al. (2011) proposed the impact on environmental variables and the physiological effects of symbiosis, which promotes homeostasis of the planet. Weaver and Dyke (2012) explain the original model of environmental self-regulation, which changes in insolation, and self-organisation of life as an important separation of timescales. Zeng et al. (1990) studied life and environment, investigating interactions to evaluate the existence of periodic and chaotic properties of the model. Rueangphankun et al. (2016a) describes the interaction between life and environment in the Daisyworld model, considering both snow and green daisies within the model. Nevison et al. (1999) modified the original model by the addition of a differential equation for temperature. This lead to periodic shifts of temperature within the model. Salazar and Poveda (2009) extended the model of Nevison et al. (1999) by incorporating the hydrological cycle and clouds as model parameters. Rueangphankun et al. (2016b) studied the numerical simulation of global environment in different scenarios of solar luminosity. Furthermore, there are also some researchers who modified the Daisyworld model of Watson and Lovelock (1983) to one-dimensional and two-dimensional aspects (Adams et al., 2003; Ackland et al., 2003; Biton and Gildor, 2012; Punithan et al., 2012).

The following studies describe how the Daisyworld model considers the greenhouse gas effect on the average temperature of Earth's atmosphere. Svirezhev and Bloh (1998) introduced a zero-dimensional climate-vegetation model containing a global carbon cycle and suggesting a new model by adding the hydrological cycle. The model describes the interaction between climate and biosphere parameters. Viola et al. (2013) explains global warming by adding greenhouse gases in the analysis, and considers 
climate variability using a sinusoidal variation of solar luminosity. Paiva et al. (2014) propose a model describing global warming with the inclusion of greenhouse gas emission and absorption rates. Alberti et al. (2015) examined a modified version of the Daisyworld model which includes spatial dependency, variable heat diffusivity and the greenhouse effect by means of a grayness function.

However, there have been few studies using the Daisyworld model to describe the effects of ice-albedo feedback on global temperature. Although the ice-albedo feedback has not been applied to the Daisyworld model, there are still researchers interested in this topic. Fraedrich (1979) shows an analysis of qualitative aspects of the global climate system with ice-albedo feedback and the greenhouse effect. Winton (2008) evaluates the potential of the sea ice-albedo feedback and nonlinearity of Arctic climate change. Mcgehee and Widiasih (2012) investigate an approximation of Budyko's icealbedo feedback model and give a simple explanation for the invariant manifold.

The objective of this study aims to modify the Daisyworld model based on the idea of how global warming is influenced by ice-albedo feedback and the greenhouse gases. In this study, the interaction between the organisms and the physical environment of the planet under the influence of global warming factors is investigated. The environment is represented by the temperature of the planet, and the organisms are represented by the black and the white daisies populations. As previously mentioned, the Daisyworld model has not been used to establish a relationship between ice-albedo feedback and global warming. Researchers have mainly focused on using Daisyworld to establish a relationship between greenhouse gases and global warming. The model in this paper is divided into three different scenarios. Each scenario considers the exclusion and inclusion of organisms. In the first scenario, a model using only ice-albedo feedback is built, as it has been linked to global warming. The second scenario focuses on the relationship between $\mathrm{CO}_{2}$ emissions and global warming. For this particular scenario, the quantification of $\mathrm{CO}_{2}$ levels in the atmosphere is divided into three mathematical expressions: constant value, linear increase and a sine function variation over a linear increase. The final scenario incorporates both the ice-albedo feedback and $\mathrm{CO}_{2}$ levels into the Daisyworld model. The temperature results of the planet from the three different model scenarios are compared.

This article is managed as follows: Section 2 explains the Daisyworld model. In Section 3 describes the modified Daisyworld model of a scenario only using the icealbedo feedback, a scenario only using $\mathrm{CO}_{2}$ levels and a scenario with both ice-albedo feedback and $\mathrm{CO}_{2}$. In Section 4 , the results and discussion of this work are illustrated. Lastly, Section 5 presents conclusions.

\section{Daisyworld model}

The original Daisyworld model represents life by daisy populations. The planet is populated by both a black and white daisy species. The daisy population is related to the change of area within the planet. The area of change is dependent on the growth and decay of each daisy species. This change in area influences the covered and uncovered areas (Fig. 2). The model represents both the growth and decay of each species population. Thus, the area changes of both daisy species can be defined by the following differential equations (Eqs. 1 and 2; Barnsley, 2007; Watson and Lovelock, 1983): 


$$
\begin{aligned}
& \frac{d \alpha_{b}}{d t}=\alpha_{b}\left(\alpha_{g} \beta_{b}-\gamma\right) \\
& \frac{d \alpha_{w}}{d t}=\alpha_{w}\left(\alpha_{g} \beta_{w}-\gamma\right)
\end{aligned}
$$

where $\alpha_{b}$ and $\alpha_{w}$ are the areas covered by the black and white daisies, respectively. $\beta_{b}$ and $\beta_{w}$ are the growth rates per unit time and unit area of the black and white daisies, respectively, $\gamma$ is the death rate per unit time of the daisies. The variable $\alpha_{g}$ is the area of bare ground in an original model represented by $(E q .3)$ :

$$
\alpha_{g}=1-\alpha_{b}-\alpha_{w}
$$

Hence, the total area covered by the bare ground and both types of daisies is equal to 1, as follows (Eq. 4; Watson and Lovelock, 1983):

$$
\alpha_{g}+\alpha_{b}+\alpha_{w}=1
$$

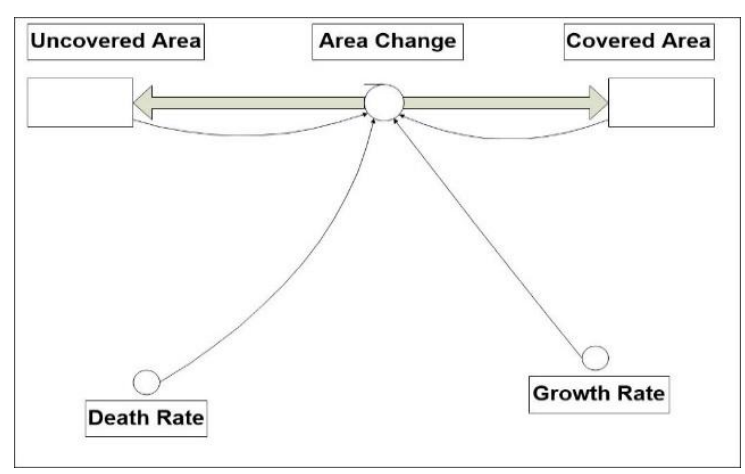

Figure 2. Basic growth model used in Daisyworld

The growth rates of the black and white daisies are assumed to be a parabolic function of local temperature (Fig. 3), as follows (Eqs. 5 and 6; Watson and Lovelock, 1983):

$$
\begin{aligned}
& \beta_{b}=1-C\left(\delta-T_{b}\right)^{2} \\
& \beta_{w}=1-C\left(\delta-T_{w}\right)^{2}
\end{aligned}
$$

where $T_{b}$ and $T_{w}$ are the local temperatures over the areas covered by the black and white daisy species, respectively. $C$ is equal to $1 /(17.5)^{2}$ while the optimal growth temperature, $\delta$, is equal to $22.5^{\circ} \mathrm{C}$. The parabolic function is zero when the local temperature is equal to $5{ }^{\circ} \mathrm{C}$ and $40{ }^{\circ} \mathrm{C}$ (Fig. 3). This means the daisy population stops growing and has a maximum value of one when the local temperature equals $22.5^{\circ} \mathrm{C}$. According to these results, the optimal temperature for daisy population growth is $22.5^{\circ} \mathrm{C}$. 


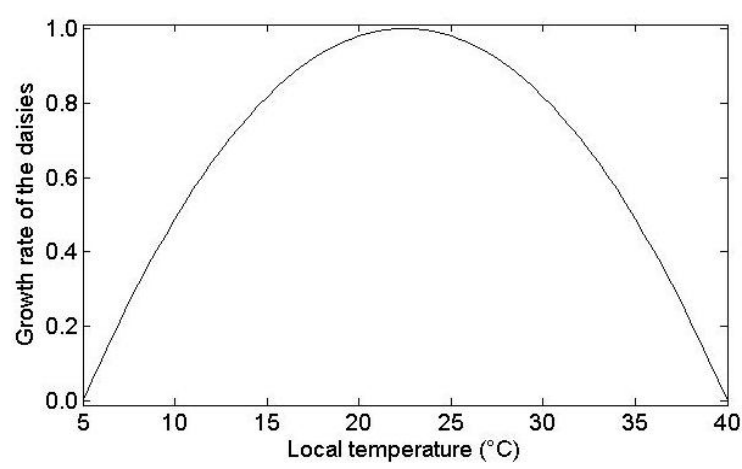

Figure 3. Relationship between the growth rate of the daisies and local temperature of each species

The local temperature of an area covered by either species of the daisies can be expressed as (Eqs. 7 and 8; Watson and Lovelock, 1983):

$$
\begin{aligned}
& T_{b}^{4}=q\left(A_{l}-A_{b}\right)+T^{4} \\
& T_{w}^{4}=q\left(A_{l}-A_{w}\right)+T^{4}
\end{aligned}
$$

where $A_{l}, A_{b}$ and $A_{w}$ are the albedos of land, the black and the white daisies, respectively, $q$, a positive constant, expresses the degree to which solar energy, after having been absorbed by the planet, $T$ is the temperature of the planet in Daisyworld. From Equations 7 and 8, the local temperature for black and white daisy species can be simplified with little error. Using a linear approximation from Taylor's theorem, Equations 7 and 8 can be expressed as (Eq. 9 and 10; Watson and Lovelock, 1983):

$$
\begin{aligned}
& T_{b}=q^{\prime}\left(A_{l}-A_{b}\right)+T \\
& T_{w}=q^{\prime}\left(A_{l}-A_{w}\right)+T
\end{aligned}
$$

where $q^{\prime}=q / 4 T^{3}$. The error introduced by this approximation is normally less than $2{ }^{\circ} \mathrm{C}$ for the temperature of interest. The albedo of the original Daisyworld varies as a function of the fraction of land or the planet surface covered by bare ground, the black and the white daisies, as well as their respective albedo values (Barnsley, 2007). All of the albedo values are between 0 and 1 . An albedo of 0 is a perfect absorber of light while 1 is a perfect reflector of light. The albedo of land, $A_{l}$, of the original model can be defined as follows (Eq. 11; Watson and Lovelock, 1983):

$$
A_{l}=\alpha_{g} A_{g}+\alpha_{b} A_{b}+\alpha_{w} A_{w}
$$

And $A_{b}<A_{g}<A_{w}$, where $A_{g}$ is the albedo of bare ground. Watson and Lovelock (1983) described the temperature of Daisyworld by absorption and emission of radiation on the planet. It can be defined as follows (Eq. 12): 


$$
e_{s a} \sigma T^{4}=S L\left(1-A_{l}\right)
$$

where $e_{s a}$ is the effective emissivity, $S$ is the solar flux constant, $L$ is the solar luminosity and $\sigma$ is the Stefan-Boltzmann constant. Emissivity is a dimensionless number that ranges from 0 to 1 . The original model of Watson and Lovelock (1983) defined $e_{s a}=1$. Nevison et al. (1999) have replaced Equation 12 with an ODE for the planet temperature, $T$, which allows $T$ to be represented in an unsteady state. The ODE can be written as (Eq. 13):

$$
c \frac{d T}{d t}=S L\left(1-A_{l}\right)-e_{s a} \sigma T^{4}
$$

where $c$ is the average heat capacity of the planet. The result of the Daisyworld model of Nevison et al. (1999) in Equation13 causes self-sustained temperature oscillations that are closely coupled to oscillations in both species of daisy populations (Fig. 4).

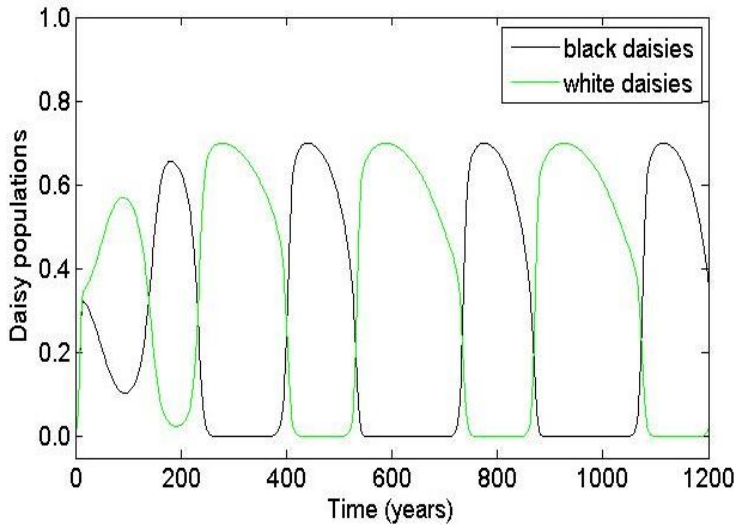

a

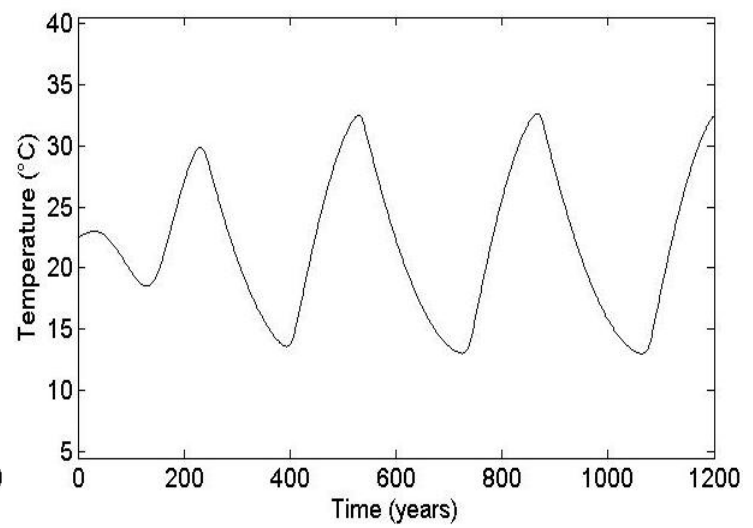

b

Figure 4. The Daisyworld model response (Nevison et al., 1999). (a) Area fraction of the black and the white daisies; (b) temperature of Daisyworld

\section{A modified Daisyworld model}

A modified Daisyworld model is developed by adding ice-albedo feedback and greenhouse gases into the Daisyworld model. There are three different scenarios including ice-albedo feedback, greenhouse gases and a combination of ice-albedo feedback and greenhouse gases. The detail of a modified Daisyworld model is shown in the following sections.

\section{A modified Daisyworld model with ice-albedo feedback}

The ice-albedo feedback scenario was applied to the Daisyworld model. In the model, the surface of the planet is divided into two parts, a fraction of land consisting of bare ground/ black and white daisies and a fraction of melting ice. Both fractions are represented by $f$ and $1-f$, respectively. The model assumes that each daisy species cannot grow in a fraction of melting ice. Thus, the total area covered by the bare ground and both species of daisy from Equation 4 can be rewritten as Equation 14 and a fraction of melting ice, $\alpha_{m}$, can be defined as Equation 15, respectively. 


$$
\begin{gathered}
\alpha_{g}+\alpha_{b}+\alpha_{w}=f \\
\alpha_{m}=1-f
\end{gathered}
$$

Therefore, the albedo of the planet in this situation depends on the fractions of land and melting ice, as defined by (Eq. 16):

$$
A_{l, m}=f A_{l}+(1-f) A_{m}
$$

Where $A_{l}$ follows Equation 11 and $A_{m}=a-b T^{2}$ is an ice-albedo feedback introduced to link variations in the planets temperature, $a$ and $b=10^{-5} \mathrm{~K}^{-2}$ represent the magnitudes of the ice-albedo feedback parameters. Therefore, the ODE in Equation 13 becomes (Eq. 17):

$$
\frac{d T}{d t}=\frac{1}{c}\left[S L\left(1-A_{l, m}\right)-e_{s a} \sigma T^{4}\right]
$$

In this situation, the effective emissivity is defined by $e_{s a}=e_{s}-e_{a}$, where $e_{s}$ is surface emissivity and $e_{a}$ is the atmospheric emittance (Fraedrich, 1979). In this work, it is defined as $a=1.4$ and $e_{s a}=0.8$.

\section{A modified Daisyworld model with greenhouse effect}

This section presents greenhouse effect as a temperature dependent feedback for atmospheric emittance, $e_{a}$, is expressed as (Eq. 18):

$$
e_{a}=e_{c}+k T^{2}
$$

where $e_{c}=0.0235 \ln \left(\mathrm{CO}_{2}\right)+c_{t}$ (Bryson and Dittberner, 1976) is formulation for carbon dioxide emittance in the atmosphere, $\left(\mathrm{CO}_{2}\right.$ in $\left.\mathrm{ppm}\right)$ and $k$ is the greenhouse effect coefficient. In this condition, Equation 18 is added into the basic ODE in Equation 13 and there is no ice albedo feedback which leads to (Eq. 19):

$$
\frac{d T}{d t}=\frac{1}{c}\left[S L\left(1-A_{l}\right)-e_{s c} \sigma T^{4}+k \sigma T^{6}\right]
$$

where $e_{s c}=e_{s}-e_{c}$ (Fraedrich, 1979). Here, $k=7 \times 10^{-7} \mathrm{~K}^{-2}$ and $c_{t}=0$. For the greenhouse gas effect, $\mathrm{CO}_{2}$ is divided into three situations; constant value, linear increase and a sine function variation over a linear increase.

\section{Constant $\mathrm{CO}_{2}$}

In the first incident with greenhouse effect, $\mathrm{CO}_{2}$ in the planet's atmosphere is assumed to remain constant. Thus, a constant value situation is considered as (Eq. 20): 


$$
\mathrm{CO}_{2}=400 \mathrm{ppm}
$$

Linear increase of $\mathrm{CO}_{2}$

According to (Kahn, 2017), human activities have committed a massive amount of $\mathrm{CO}_{2}$ to the atmosphere. It has driven $\mathrm{CO}_{2}$ levels to record highs year after year. $\mathrm{He}$ found that globally averaged concentrations of $\mathrm{CO}_{2}$ have a rate of increasing about 3 ppm per year from 2015 to present. To represent annual rates of $\mathrm{CO}_{2}$ increases in the atmosphere, linear increasing function is defined as $3 \mathrm{ppm}$ per year for indicating the behavior of $\mathrm{CO}_{2}$ (Fig. 5a). The equation can be expressed as (Eq. 21):

$$
\mathrm{CO}_{2}=400+3 t \mathrm{ppm}
$$

A sine function variation over a linear increase of $\mathrm{CO}_{2}$

Under this event, the fluctuation of atmospheric $\mathrm{CO}_{2}$ will not increase at a linear rate but have a tendency to increase continuously (Fig. $5 b$ ). The sine function has been incorporated into Equation 21. Therefore, the instantiation of sine function variation over a linear increase is determined as (Eq. 22):

$$
\mathrm{CO}_{2}=(400+3 t)+(A \sin B t) p p m
$$

where the value of $A$ and $B$ refer to amplitude and time, respectively.

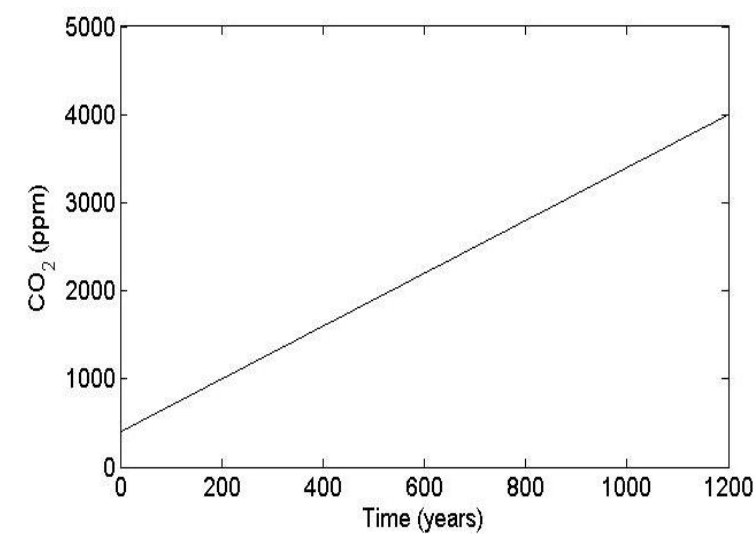

$\mathbf{a}$

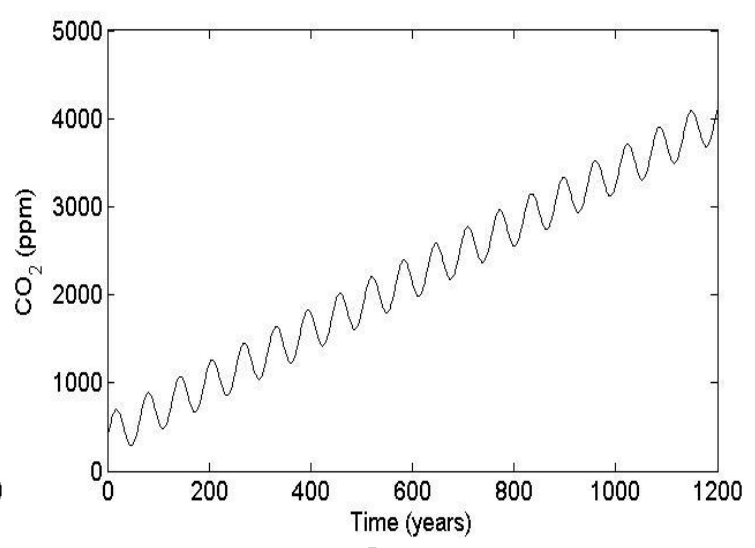

b

Figure 5. A different of increasing of the $\mathrm{CO}_{2}$ concentration in the atmosphere. (a) Linear increase; (b) a sine function variation over a linear increase

\section{A modified Daisyworld model with ice-albedo feedback and greenhouse effect}

The final model scenario suggests a combination of ice-albedo feedback and $\mathrm{CO}_{2}$ levels. According to Equation 13, the following equation can be expressed as (Eq. 23; Fraedrich, 1979):

$$
\frac{d T}{d t}=\frac{1}{c}\left[S L\left(1-A_{l, m}\right)-e_{s c} \sigma T^{4}+k \sigma T^{6}\right]
$$




\section{Results and discussion}

Euler's method is used to connect with an iterative process to simulate three different scenarios: ice-albedo feedback; $\mathrm{CO}_{2}$ levels; and a combination of ice-albedo feedback and $\mathrm{CO}_{2}$ levels. Each of the above scenarios are considered as including or excluding organisms. The $\mathrm{CO}_{2}$ levels are divided into three parts: constant value, linear increase and a sine function variation over a linear increase. The values of the parameters for each modelled scenario is shown in Table 1.

Table 1. Parameter values of Daisyworld model

\begin{tabular}{c|c|c|c}
\hline Symbol & Parameter value & Unit & Source of information \\
\hline$A_{g}$ & 0.5 & Dimensionless & (Watson and Lovelock, 1983) \\
$A_{b}$ & 0.25 & Dimensionless & (Watson and Lovelock, 1983) \\
$A_{w}$ & 0.75 & Dimensionless & (Watson and Lovelock, 1983) \\
$\gamma$ & 0.3 & Dimensionless & (Watson and Lovelock, 1983) \\
$q^{\prime}$ & 20 & $\mathrm{~K}$ & (Watson and Lovelock, 1983) \\
$\sigma$ & 1789 & $\mathrm{erg} \cdot \mathrm{cm}^{-2} \cdot \mathrm{yr}^{-1} \cdot \mathrm{K}^{-4}$ & (Nevison et al., 1999) \\
$S$ & $2.89 \times 10^{13}$ & $\mathrm{erg} \cdot \mathrm{cm}^{-2} \cdot \mathrm{yr}^{-1}$ & (Nevison et al., 1999) \\
$L$ & 1 & $\mathrm{dimensionless}$ & (Watson and Lovelock, 1983) \\
$c$ & $3 \times 10^{13}$ & $\mathrm{erg} \cdot \mathrm{cm}^{-2} \cdot \mathrm{K}^{-1}$ & (Nevison et al., 1999) \\
$q$ & $2.06 \times 10^{9}$ & $\mathrm{~K}^{4}$ & (Paiva et al., 2014) \\
\hline
\end{tabular}

\section{Ice-albedo feedback}

In the situation of ice-albedo feedback, the consequences of the model including and excluding the daisies represents the temperature of the planet including and excluding organisms. Figure 6 displays the temperature of the planet excluding the daisies. The resulting plot for a planet without organisms indicates that the planet's temperature begins at $22.5^{\circ} \mathrm{C}$ and increases rapidly to $105{ }^{\circ} \mathrm{C}$ under a timeframe of 600 years. After 600 years, the temperature of the planet only slightly varies. After reaching $110{ }^{\circ} \mathrm{C}$ at 800 years, the planets temperature no longer changes. The model including black and white daisy species (i.e. organisms) was initially set to $f=0.9$. Whereby the value of $f$ represents the fraction of bare surface and daisy species coverage (Fig. 7). The fraction that equals 0.1 represents the melting of ice, $1-f$, as a result of ice-albedo feedback. Also, Figure $7 a$ presents the fractional areas covered by the black and the white daisy species on the planet. While Figure $7 b$ represents the temperature of Daisyworld due to ice-albedo feedback and the interaction between two species of daisy populations as in Figure $7 a$. The interaction confines the temperature values within a reasonable range for life continuation. The increase of the white daisies is more evident as the planet's average temperature decreases. The increase of black daisies is more evident as the average temperature of the planet increases. The modelled results of $f=0.9$ for average planet temperature ranged between a minimum value of $17.5^{\circ} \mathrm{C}$ and a maximum value of $26.5^{\circ} \mathrm{C}$.

The Daisyworld model was also set to $f=0.8$ for the representation of bare surface along with black and white daisy species (Fig. 8). Figure $8 a$ illustrates the change in 
black and white daisy populations overtime, while Figure $8 b$ shows the temperature of the planet over the same temporal scale. The results show that the planet's maximum temperature value was $25^{\circ} \mathrm{C}$ during the first two decades and then falls to a minimum value of $18.5^{\circ} \mathrm{C}$ in the following 580 years. After 200 years, there is only a minute change in the planet's temperature. The fraction of light area for each daisy population begins at 0.01 (Fig. 8a). In a short period of time white daisies are shown to grow almost instantaneously. At around 0.7, the growth of white daisies becomes stagnant. During the growth of white daisies, black daisy population dramatically decreases. Eventually becoming stagnant along with the white daisy population.

Figures 9-11 illustrate models representing ice-albedo feedback with different fractional values; $f=0.7,0.6$ and 0.5 , respectively. The consequence for $f=0.7$ in Figure 9 elucidates that the initial temperature of the planet is $22.5^{\circ} \mathrm{C}$. The temperature increases to $25{ }^{\circ} \mathrm{C}$ and subsequently declines to a steady state of $21{ }^{\circ} \mathrm{C}$ at 400 years. Similar to the previous model where ice-albedo feedback is set at $f=0.8$, the white daisy population under $f=0.7$ grows increasingly fast, from $0.01-0.7$, over a short period of time (Fig. 9). The population growth for white daisies becomes stagnant, hovering around 0.7 after 50 years. Similarly, the black daisy population decreases quickly, from 0.3 to 0.0 , over a short period of time. The population eventually dies out after 50 years. There is a similar outcome to the model representing ice-albedo feedback at a value of $f=0.6$. A sharp increase is illustrated by the white daisy population under a short period of time, while there is a sharp decrease in black daisy population over a short period of time. Both populations taper off into a steady state of no growth after 50 years (Fig. 10). The model representing an ice-albedo feedback of $f=0.5$ illustrates that the average temperature of the planet continuously increases from $22.5{ }^{\circ} \mathrm{C}$ to $36.5^{\circ} \mathrm{C}$ over 1200 years (Fig. 11b). While the temperature gradually increases, the white daisy population increases sharply over the first 50 years of the simulation. After 50 years, the white daisies tend to decrease continuously. The black daisy population decreases from 0.3 to 0.0 over the first 50 years of the simulation (Fig. 11a).

Finally, Figure 12 illustrates an event of ice-albedo feedback with a fractional value of $f=0.4$. The results show that the average temperature continuously increases from $22.5^{\circ} \mathrm{C}$ to more than $40{ }^{\circ} \mathrm{C}$, over the first 400 years. Under this scenario, the balance between both daisy populations and the plant's temperature illustrates inconsistent results. The decline of growth in the white daisy population occurs under a shorter period of time ( 400 years). While the decline of black daisy population is similar to the former simulations (Fig. 12a). Eventually, the black daisies become extinct in a short period, and the white daisies go extinct after 380 years.

Under the Daisyworld simulation excluding organisms, the average temperature of the planet increases continuously, eventually leveling out around 600 years. If the Earth's temperature ever reached the values simulated in the first model, the daisies would not survive. Contrary to the simulation with organisms, the planet's average temperature rises at a slower rate with the presence of black and white daisy populations. Black and white daisy populations alter the planet's surface temperature. However, when the fraction of land decreases along with the fraction of melting ice, there is a noticeable increase in the planet's average temperature. Moreover, the excessive increase of the planet's temperature is due to the decrease of the fraction of land, inducing the extinction of life. Hence, ice-albedo feedback is an important factor to engender global warming. 


$$
\text { - } 1494 \text { - }
$$

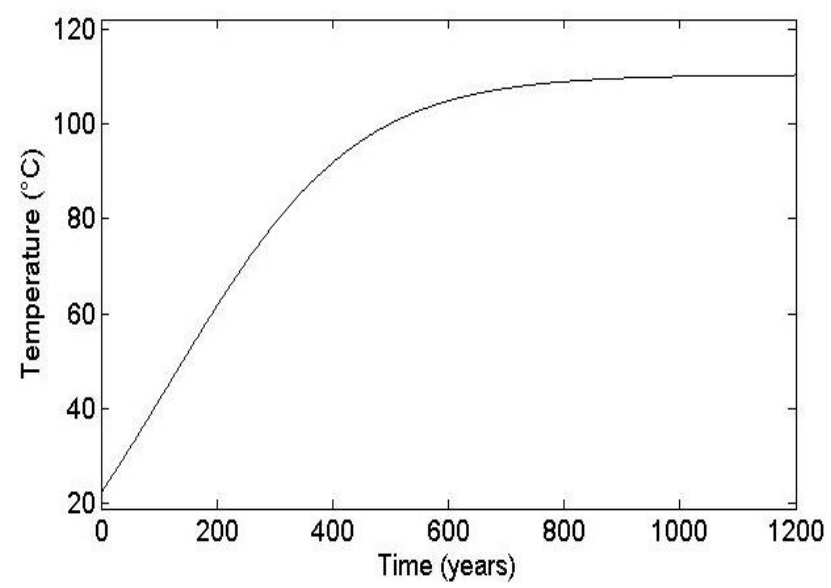

Figure 6. Temperature of the planet without organisms for ice-albedo feedback

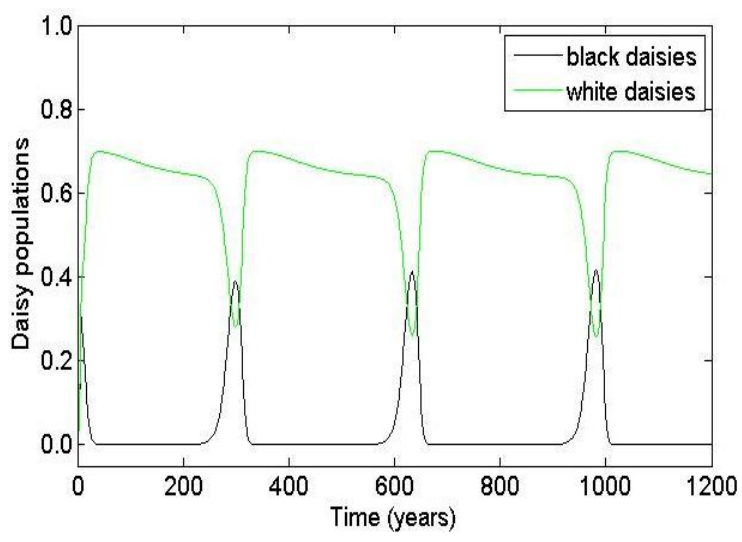

a

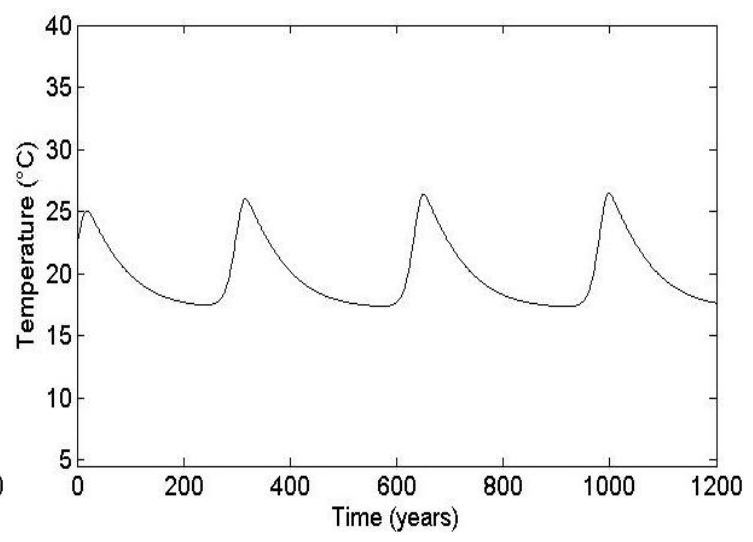

b

Figure 7. Model including organisms for ice-albedo feedback where $f=0.9$. (a) Area fraction of the black and the white daisies; (b) temperature of Daisyworld

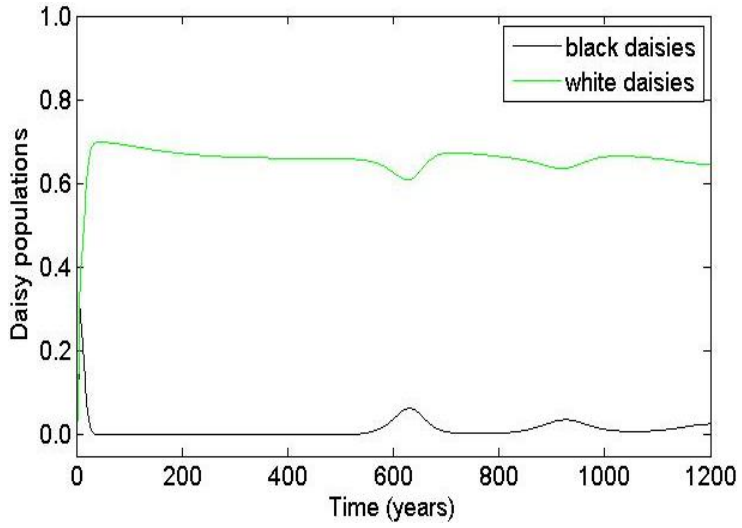

a

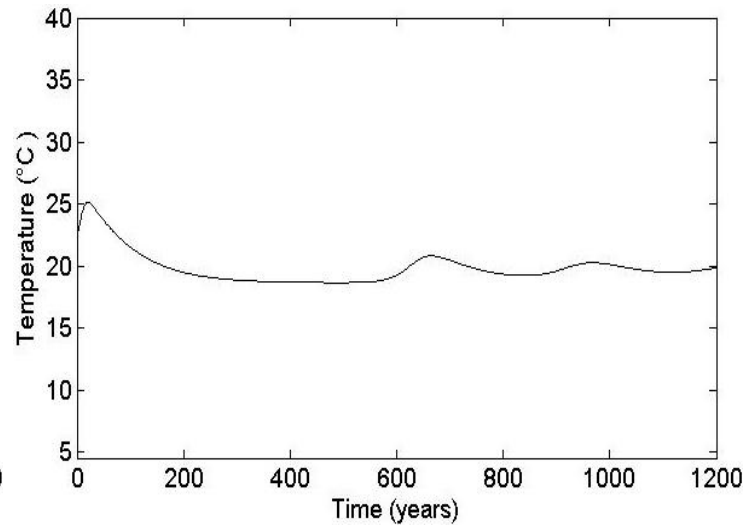

b

Figure 8. Model including organisms for ice-albedo feedback where $f=0.8$. (a) Area fraction of the black and the white daisies; (b) temperature of Daisyworld 


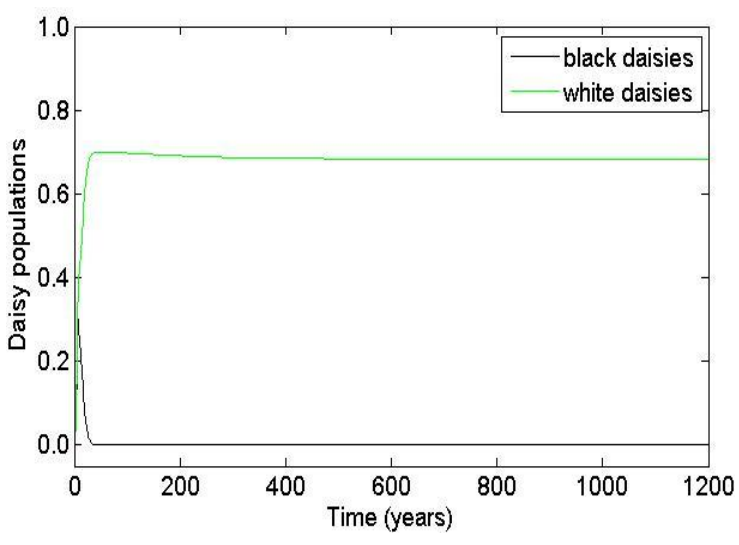

a

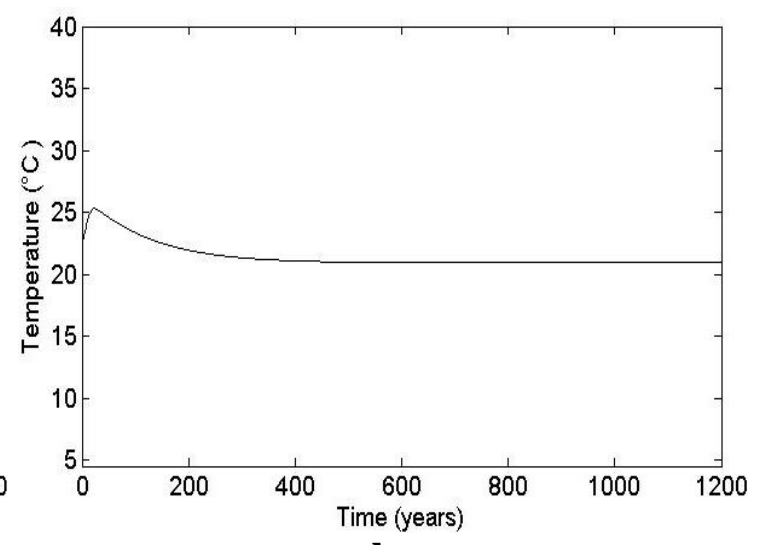

b

Figure 9. Model including organisms for ice-albedo feedback where $f=0.7$. (a) Area fraction of the black and the white daisies; (b) temperature of Daisyworld

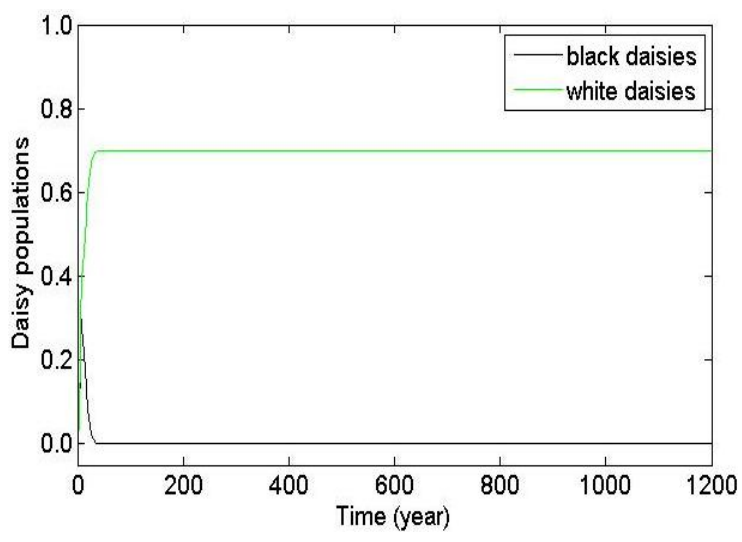

a

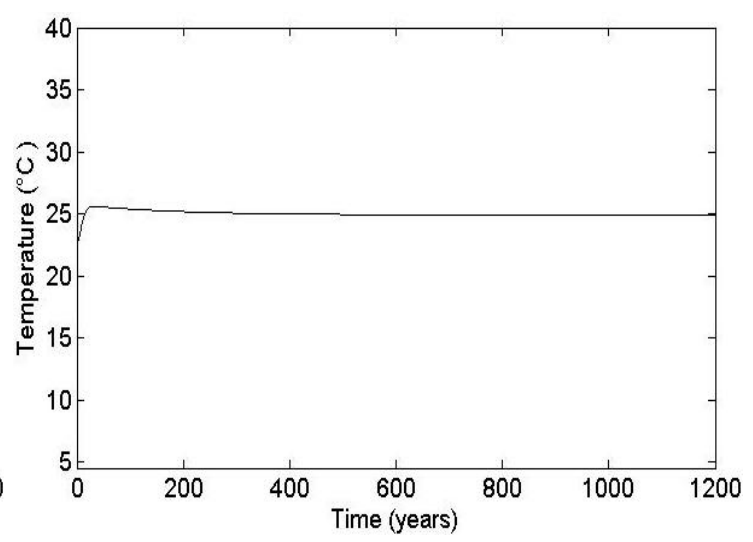

b

Figure 10. Model including organisms for ice-albedo feedback where $f=0.6$. (a) Area fraction of the black and the white daisies; (b) temperature of Daisyworld

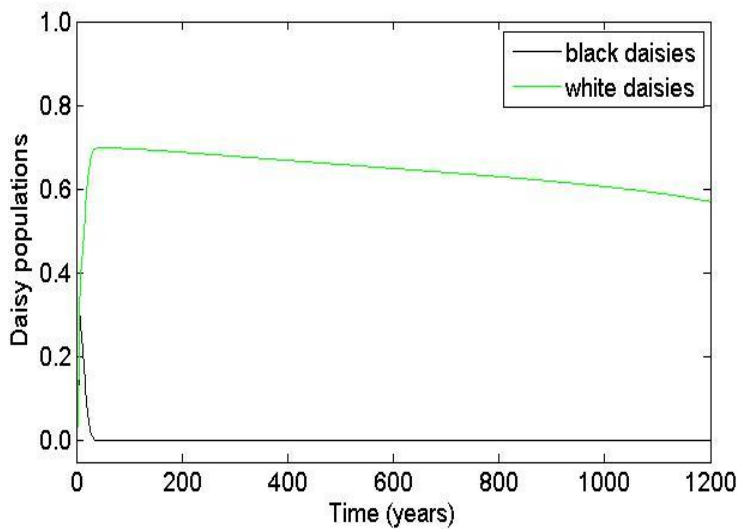

a

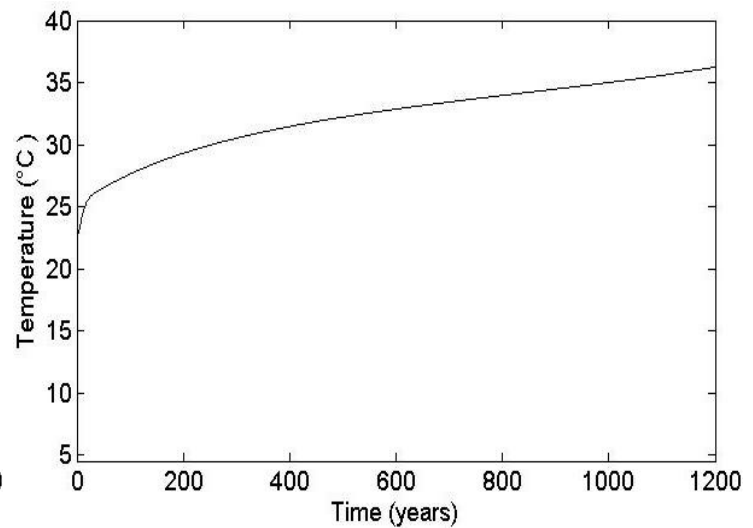

b

Figure 11. Model including organisms for ice-albedo feedback where $f=0.5$. (a) Area fraction of the black and the white daisies; (b) temperature of Daisyworld 


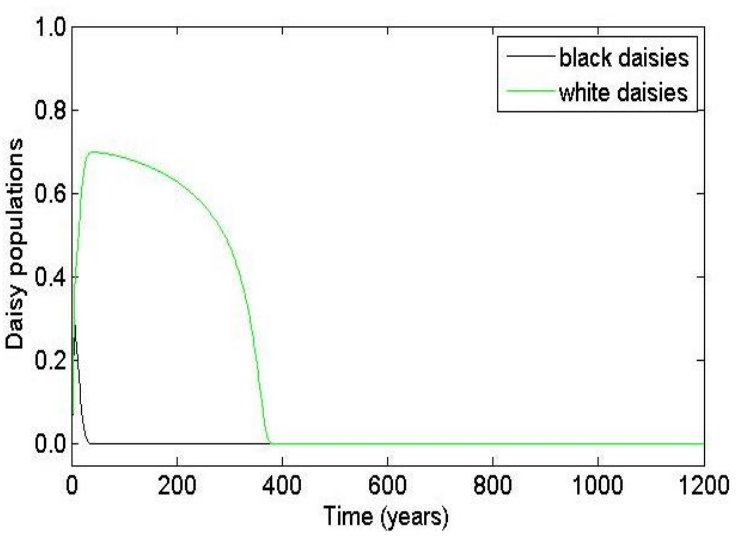

a

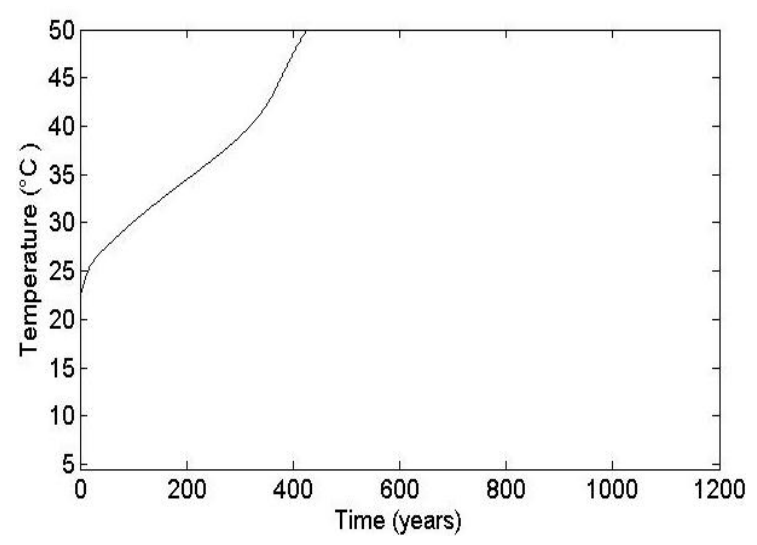

b

Figure 12. Model including organisms for ice-albedo feedback where $f=0.4$. (a) Area fraction of the black and the white daisies; (b) temperature of Daisyworld

\section{Greenhouse effect}

Greenhouse gases are represented as $\mathrm{CO}_{2}$ for the simulation of greenhouse effect on the planet's average temperature. The model in this section both incorporates the inclusion and exclusion of organisms. Firstly, the comparison of the planet's average temperature with respect to the absence of organisms and the effect of $\mathrm{CO}_{2}$ levels in the planet's atmosphere have been simulated (Fig. 13). Figures 13a, b and $c$ present three mathematical expressions for determining the planet's average temperature under the effects of $\mathrm{CO}_{2}$ : a constant value, linear increase and sine function variation over a linear increase. Each simulation begins with an average temperature of $22.5{ }^{\circ} \mathrm{C}$, gradually increasing overtime (Fig. 13). Under the scenario where $\mathrm{CO}_{2}$ is modelled with a constant value, the average temperature increases sharply within the first 250 years. Eventually leveling out at $45{ }^{\circ} \mathrm{C}$ (Fig. 13a). For scenario two, representing a linear increase, the average temperature sharply increases within the first 250 years. The temperature slightly increases and eventually levels off around $50{ }^{\circ} \mathrm{C}$ over the following 950 years (Fig. 13b). Under the last scenario, representing a sine function over a linear increase, the results illustrate similarities with the second scenario. However, the variability in $\mathrm{CO}_{2}$ for scenario three creates an instability in the rise of temperature. Over the first 200 years, the temperature sharply rises to $45{ }^{\circ} \mathrm{C}$. Afterwards, the temperature gradually rises to $50{ }^{\circ} \mathrm{C}$ over the following 1000 years (Fig. 13c). After comparing all three mathematical expressions for $\mathrm{CO}_{2}$ levels, it is found that the average global temperature in Figures $13 b$ and $c$ are higher than in Figure 13a.

A scenario in which organisms are present within the $\mathrm{CO}_{2}$ model have been simulated (Fig. 14). The simulated results illustrate that both black and white daisy populations fluctuate under the shifts in average planet temperature (Fig. 14a, b). The fluctuation of black and white daisy populations is similar to the results in Figure 7 . The varied species of daisy react to the differences in temperature. As temperature rises, black daisy population increases. As temperatures decrease, white daisy population increases. Since the white daisies have a high albedo, the average temperature of the planet decreases. Thus, giving rise to the black daisy population. Black daisies have a lower albedo; the average temperature of the planet increases. As the average temperature of the planet decreases, there is an increase in white daisy population. 


$$
\text { - } 1497 \text { - }
$$

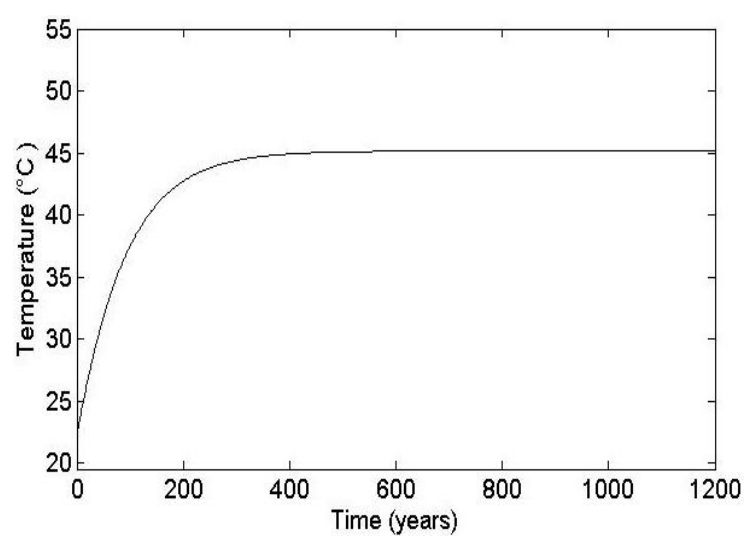

$\mathbf{a}$

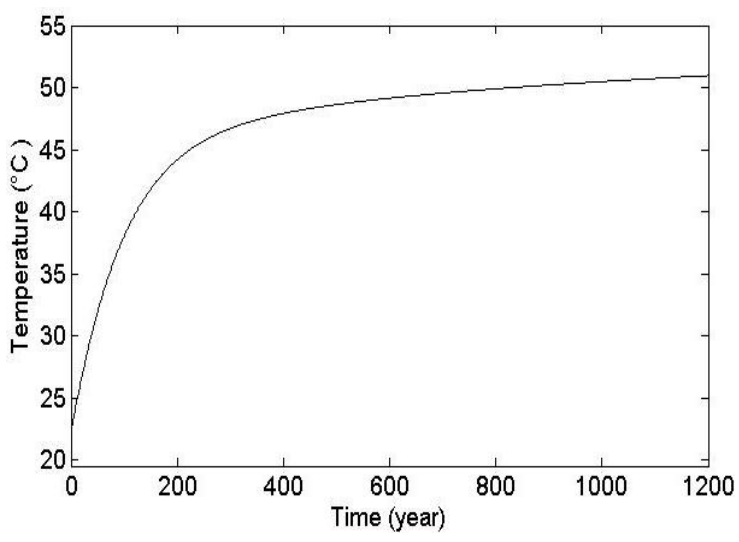

b

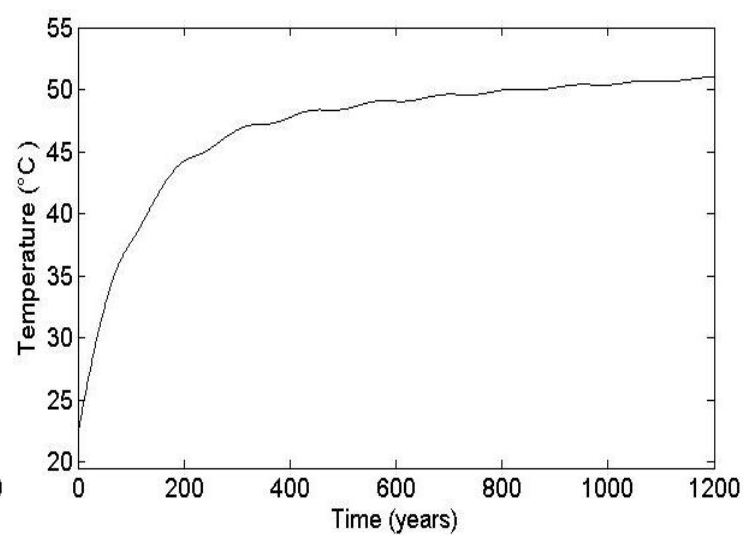

c

Figure 13. Temperature of the planet without organisms for greenhouse effect with different $\mathrm{CO}_{2}$ values. (a) Constant value; (b) linear increase; (c) a sine function variation over a linear increase

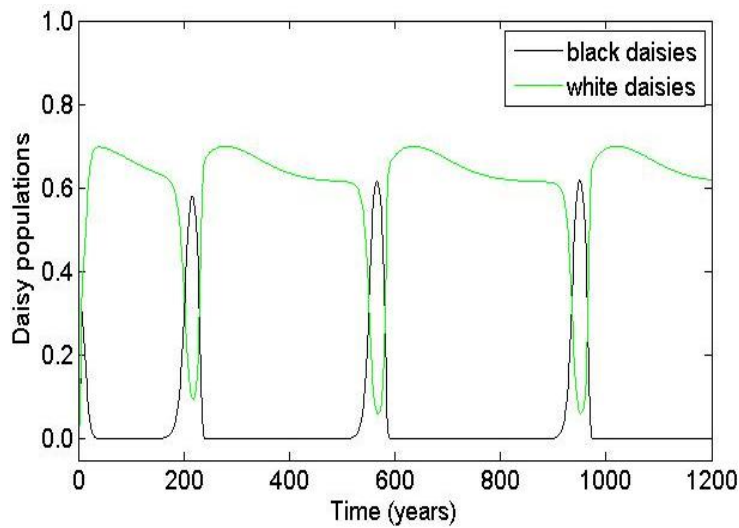

a

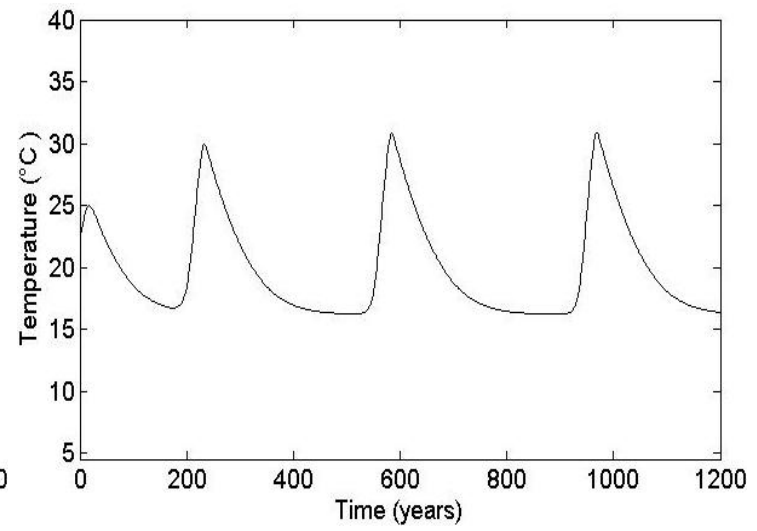

b

Figure 14. Model including organisms for greenhouse effect with constant $\mathrm{CO}_{2}$. (a) Area fraction of the black and the white daisies; (b) temperature of Daisyworld

The maximum average temperature of the planet was $30{ }^{\circ} \mathrm{C}$, while the average minimum temperature was $16{ }^{\circ} \mathrm{C}$. Modelling $\mathrm{CO}_{2}$ in a linear increase fashion (Fig. 15) 
corresponds with an increase in white daisy population and a decrease in black daisy population. The average temperature of the planet has a maximum value of $26^{\circ} \mathrm{C}$ and a minimum value of $17^{\circ} \mathrm{C}$ in the first 400 years. After 400 years, the effect of $\mathrm{CO}_{2}$ levels influences the differences in average temperature by $2{ }^{\circ} \mathrm{C}$. The maximum average temperature during this timeframe is $21^{\circ} \mathrm{C}$ while the minimum average temperature is $19{ }^{\circ} \mathrm{C}$. Under these conditions, the white daisy population proliferates while the black daisy population struggles to increase at any rate (Fig. 15). Overtime and due to the slow rise in $\mathrm{CO}_{2}$ levels, the black daisy population will become extinct. The final $\mathrm{CO}_{2}$ scenario presents a model of $\mathrm{CO}_{2}$ levels fitted to a sine function variation over a linear increase (Fig. 16). The outcome of results illustrates a resemblance to the second scenario, in that the variation of daisy population and average temperature are similar over the temporal scale. Although, the average maximum temperature for the first 400 years is $27.5^{\circ} \mathrm{C}$, higher than the results of the second $\mathrm{CO}_{2}$ scenario (Fig. 16).

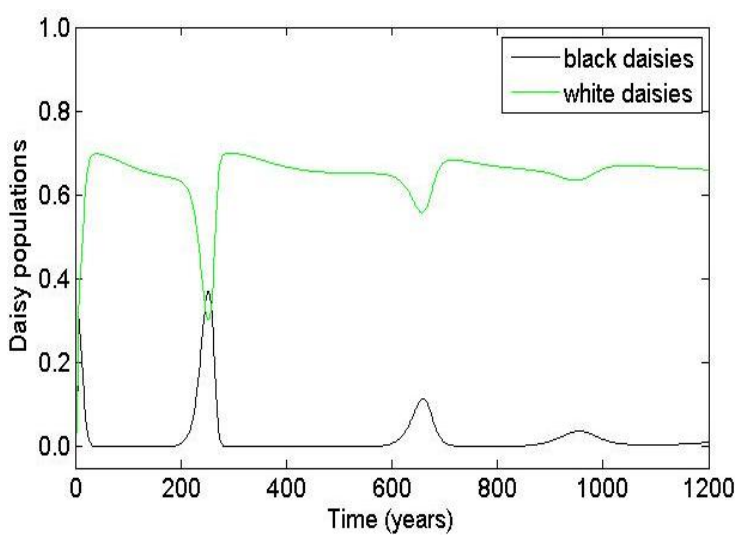

$\mathbf{a}$

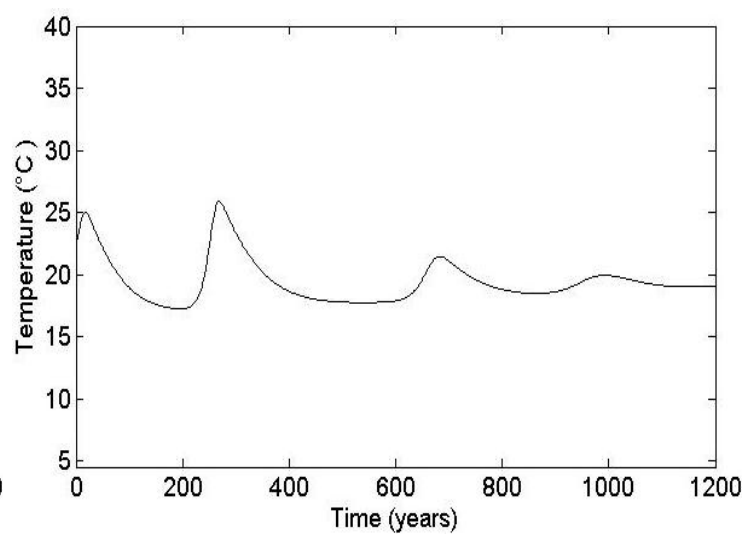

b

Figure 15. Model including organisms for greenhouse effect with linear increase of $\mathrm{CO}_{2} \cdot(a)$ Area fraction of the black and the white daisies; (b) temperature of Daisyworld

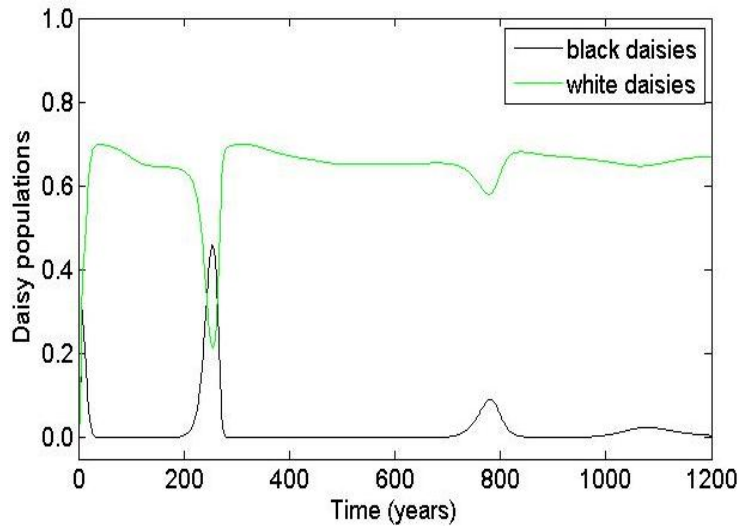

a

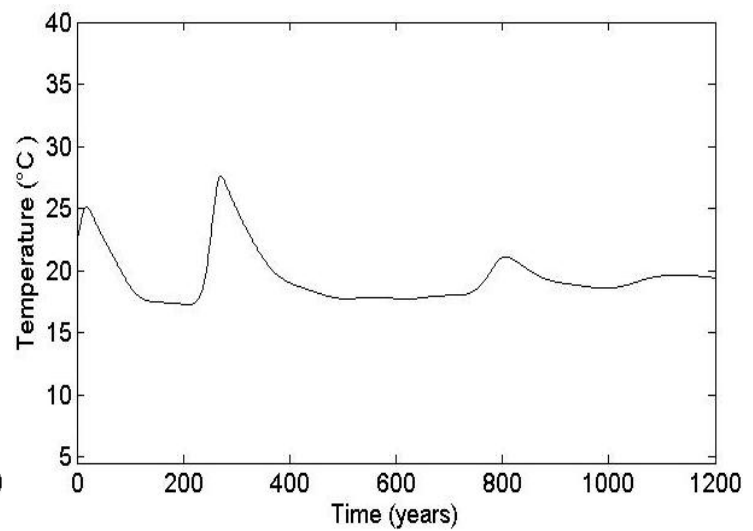

b

Figure 16. Model including organisms for greenhouse effect with a sine function variation over a linear increase of $\mathrm{CO}_{2}$. (a) Area fraction of the black and the white daisies; (b) temperature of Daisyworld 
Under the scenario where there are no organisms present on the planet and $\mathrm{CO}_{2}$ is subjected to three different mathematical expressions, the average temperature sharply increases for the first 200 years and steady increases thereafter for the following 1000 years. It is evident that under the three expressions, $\mathrm{CO}_{2}$ influences the rise in average temperature of the planet. When the planet is inhabited by white and black daisies, the different species influence the fluctuation of the planet's average temperature. The average temperatures are influenced by the adjustments of each species. However, the influence of $\mathrm{CO}_{2}$ also impacts the average temperature overtime. Thus, forcing one species to become extinct while the other proliferates. The species in this situation is the white daisy. The white daisy can tolerate higher temperatures. While the black daisy species has a higher tolerance for lower temperature environments.

\section{Ice-albedo feedback and greenhouse effect}

The final scenario proposes an incident where the combination of ice-albedo feedback and greenhouse effect $\left(\mathrm{CO}_{2}\right.$ levels) are simulated within the model. As in the previous scenario, $\mathrm{CO}_{2}$ levels are projected under the three mathematical expressions; constant value, linear increase and a sine function variation over a linear increase. The first model considers the average temperature of the planet without the existence of organisms. The initial average temperature of the planet is recorded at $22.5{ }^{\circ} \mathrm{C}$ for all three mathematical expressions. The average temperature under the first mathematical expression gradually rises to $132{ }^{\circ} \mathrm{C}$, at which the temperature reaches a steady state after 1060 years (Fig. 17a). The average temperature of the second and third mathematical expression levels out at $160{ }^{\circ} \mathrm{C}$ after 1200 years (Fig. 17b, c). The characteristic of average temperature for the three mathematical expressions in this scenario are very similar to that of the scenario representing just $\mathrm{CO}_{2}$ levels and excluding the presence of organisms.

The second model considers an instance where organisms are present on the planet with the impact of both ice-albedo feedback and $\mathrm{CO}_{2}$ levels. Under the condition where $f=0.9$ and $\mathrm{CO}_{2}$ levels are under a constant mathematical expression, white daisy population proliferates within the first 20 years. The population then levels out for the next 580 years (Fig. 18a). The black daisies become extinct within the first 20 years of the simulation. The average temperature is initially recorded at $22.5{ }^{\circ} \mathrm{C}$ but sharply increases to $28.5{ }^{\circ} \mathrm{C}$ within the first 20 years. After which the average temperature levels out at $30.5{ }^{\circ} \mathrm{C}$ for the remainder of the simulation timeframe (Fig. 18b). Where $f=0.8$ and $\mathrm{CO}_{2}$ levels are under a constant mathematical expression, the planet's average temperature exceeds $40{ }^{\circ} \mathrm{C}$ within the first 150 years (Fig. 19b). The sharp increase in temperature under a short period of time results in both the black and white daisy species to become extinct within 125 years. Albeit the white daisy population outlasts the black daisy population by roughly 100 years (Fig. 19a).

The linear increase mathematical expression was applied to the $\mathrm{CO}_{2}$ levels in combination with ice-albedo feedback at $f=0.9$ and 0.8 . Where $f=0.9$ there is an initial sharp increase of average temperature in the first 20 years. The average temperature then gradually rises to a maximum of $50{ }^{\circ} \mathrm{C}$ over the next 560 years (Fig. $20 b$ ). The initial sharp increase in temperature results in the black daisy becoming extinct after 25 years. While the white daisy species slowly dies out and eventually becomes extinct after 550 years (Fig. 20a). Similarly, the mathematical expression of a linear increase for $\mathrm{CO}_{2}$ levels illustrated temperatures exceeding $40{ }^{\circ} \mathrm{C}$ in just under 110 years (Fig. 21b). The subsequent effects resulted in the black daisy becoming 


$$
-1500
$$

extinct after 25 years, while white daisy became extinct after 125 years (Fig. 21a). The white daisies existence is longer when $f=0.9$ is applied to linear increase. The black daisy species does not fare well in either of the scenarios, becoming extinct within 25 years in both models.

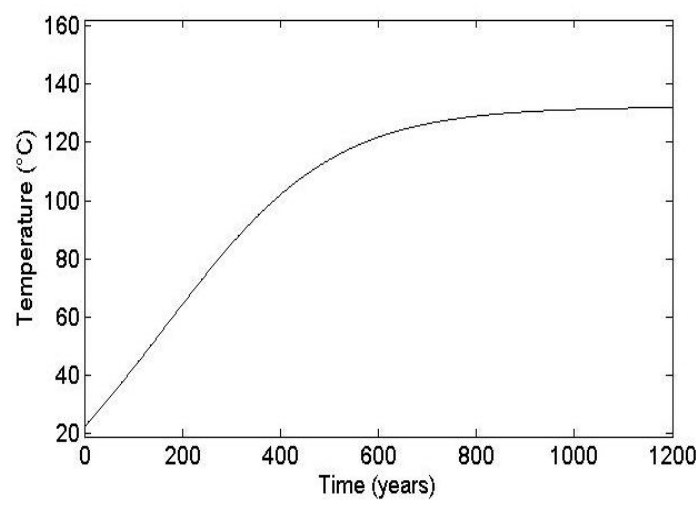

$\mathbf{a}$

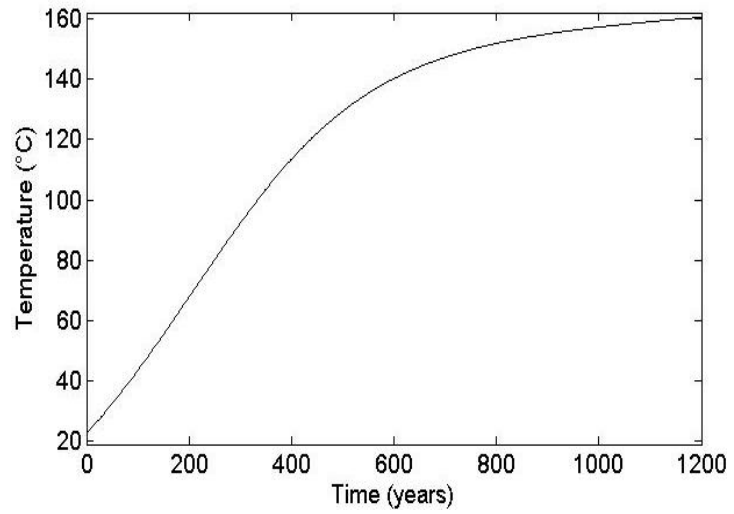

b

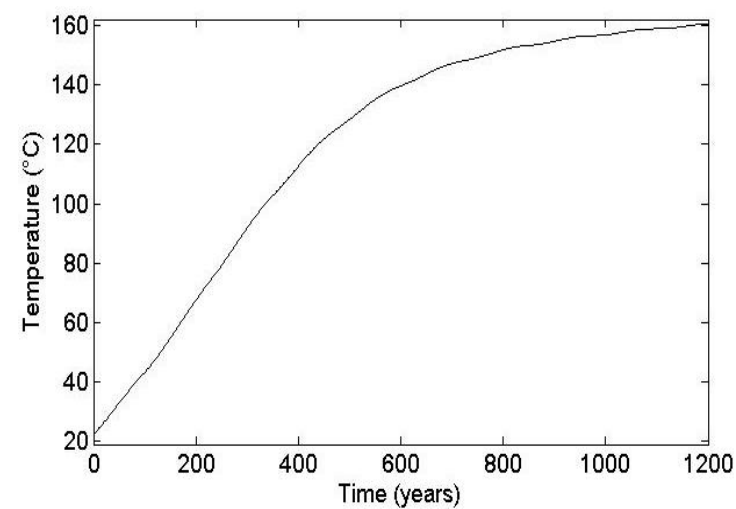

Figure 17. Temperature of the planet without organisms for both ice-albedo feedback and greenhose effect with different $\mathrm{CO}_{2}$. (a) Constant value; (b) linear increase; (c) a sine function variation over a linear increase

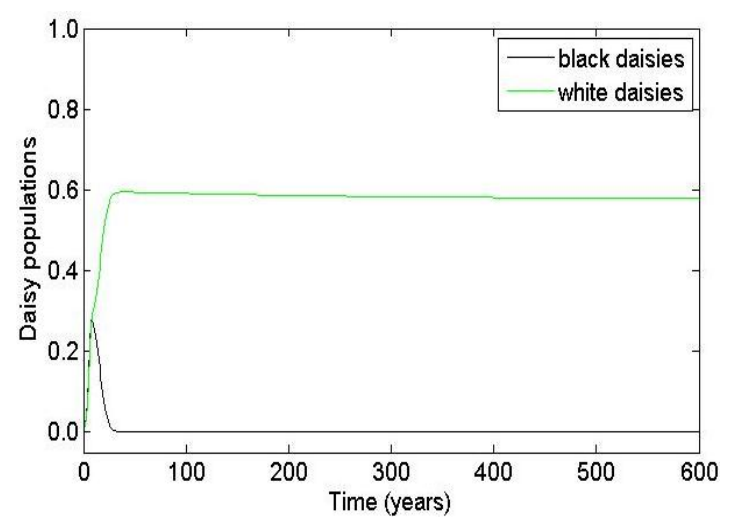

a

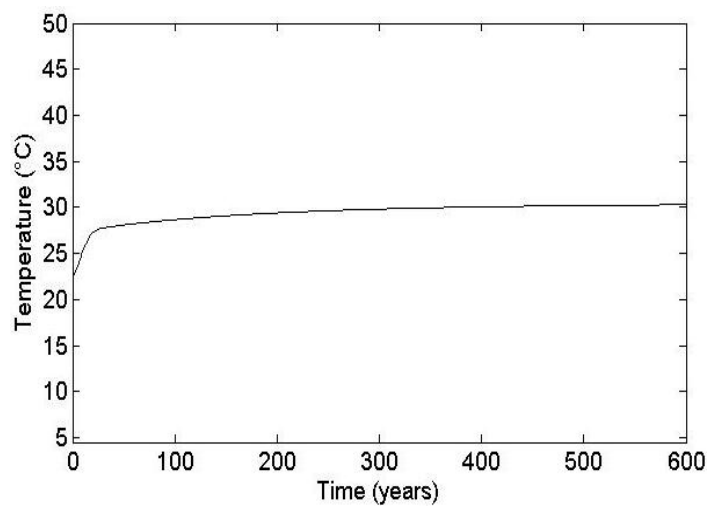

b

Figure 18. Model including organisms for both ice-albedo feedback and greenhouse effect where $f=0.9$ and constant $\mathrm{CO}_{2}$. (a) Area fraction of the black and the white daisies; (b)

temperature of Daisyworld 


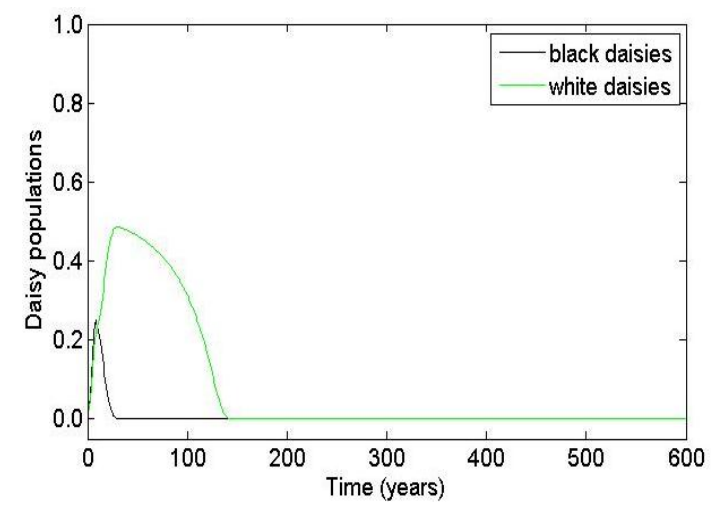

$\mathbf{a}$

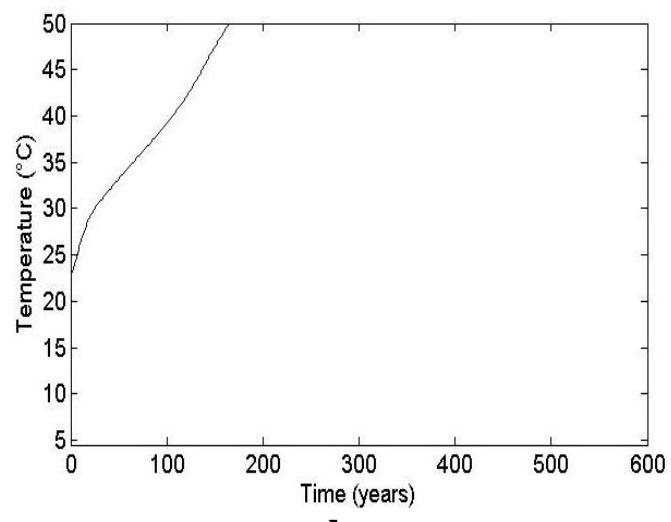

b

Figure 19. Model including organisms for both ice-albedo feedback and greenhouse effect where $f=0.8$ and constant $\mathrm{CO}_{2}$. (a) Area fraction of the black and the white daisies; (b) temperature of Daisyworld

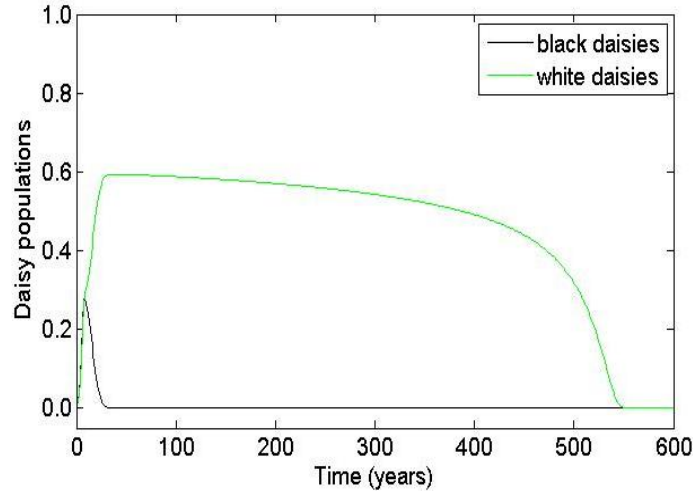

a

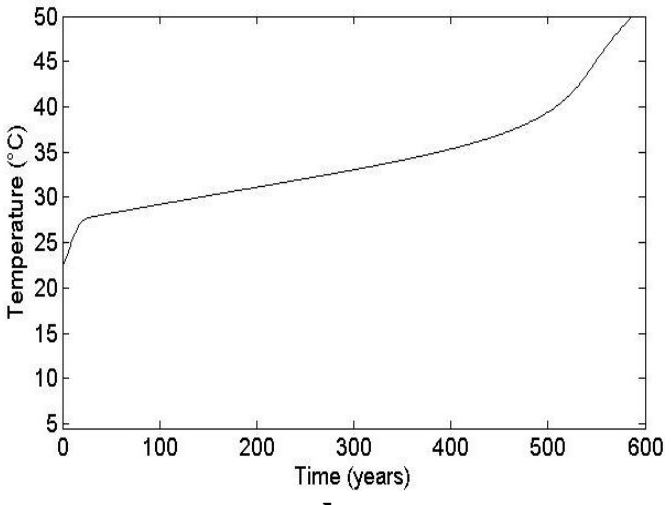

b

Figure 20. Model including organisms for both ice-albedo feedback and greenhouse effect where $f=0.9$ and linear increase of $\mathrm{CO}_{2}$. (a) Area fraction of the black and the white daisies;

(b) temperature of Daisyworld

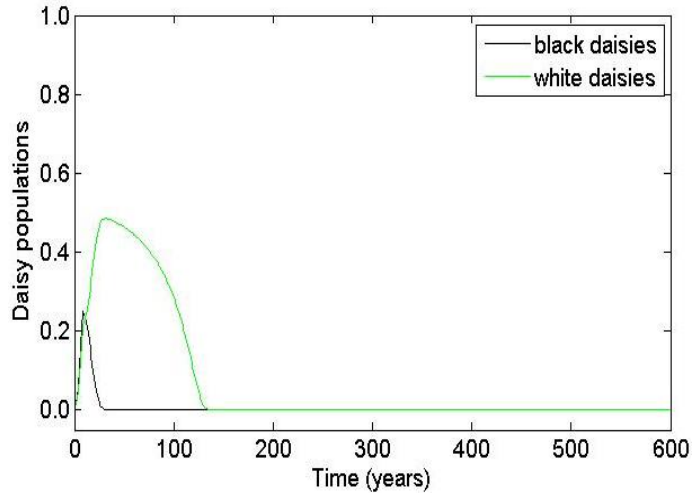

$\mathbf{a}$

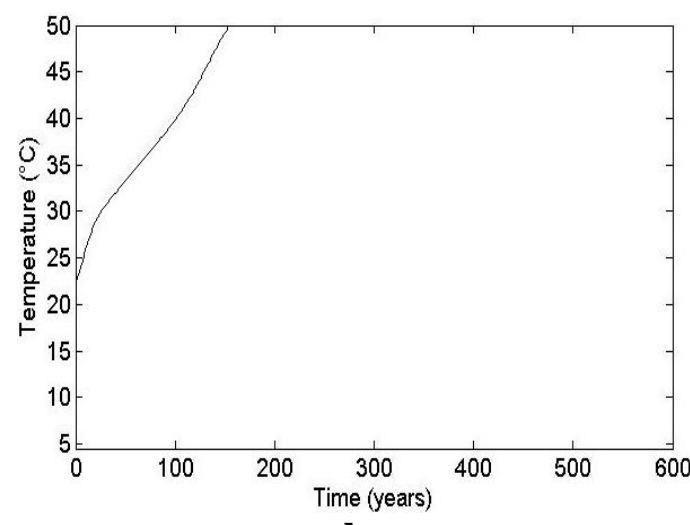

b

Figure 21. Model including organisms for both ice-albedo feedback and greenhouse effect where $f=0.8$ and linear increase of $\mathrm{CO}_{2}$. (a) Area fraction of the black and the white daisies;

(b) temperature of Daisyworld 
The final scenario introduces a sine function over a linear increase for modelling $\mathrm{CO}_{2}$ levels. Two experiment cases of $f=0.9$ and 0.8 are applied. The results illustrate similar outcomes with the previous linear function scenario. The shape of each graph is near identical to Figures 20 and 21. Where $f=0.9$ the temperature has an initial sharp increase and gradually rises to $50{ }^{\circ} \mathrm{C}$ over the next 550 years (Fig. 22b). Black daisies become extinct after just 25 years, while white daisies become extinct after 550 years (Fig. 22a). The results for $f=0.8$ are closely related to the linear function results for $f=0.8$ (Fig. 23a, b).

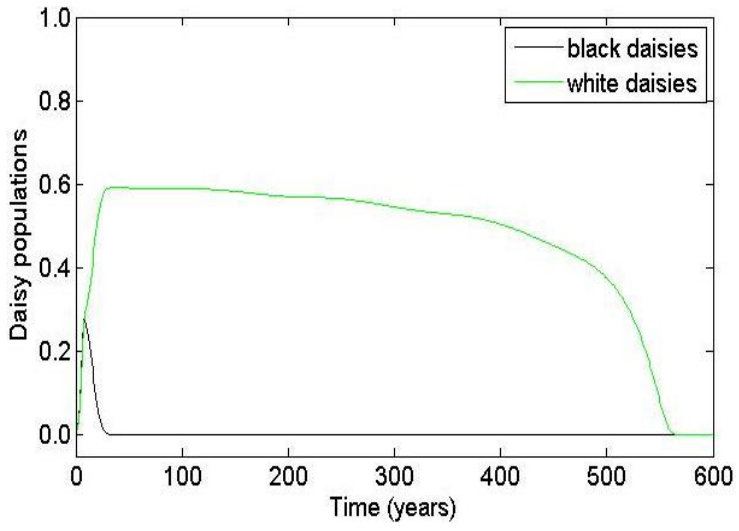

$\mathbf{a}$

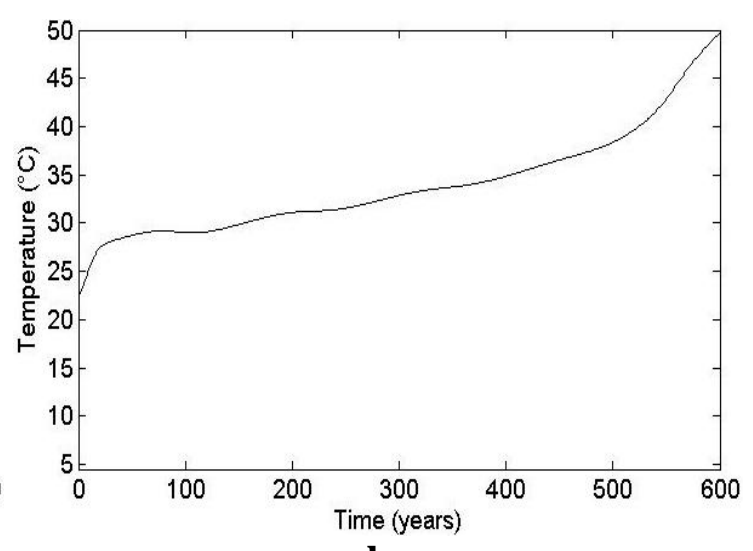

b

Figure 22. Model including organisms for both ice-albedo feedback and greenhouse effect where $f=0.9$ and a sine function variation over a linear increase of $\mathrm{CO}_{2}$. (a) Area fraction of the black and the white daisies; (b) temperature of Daisyworld

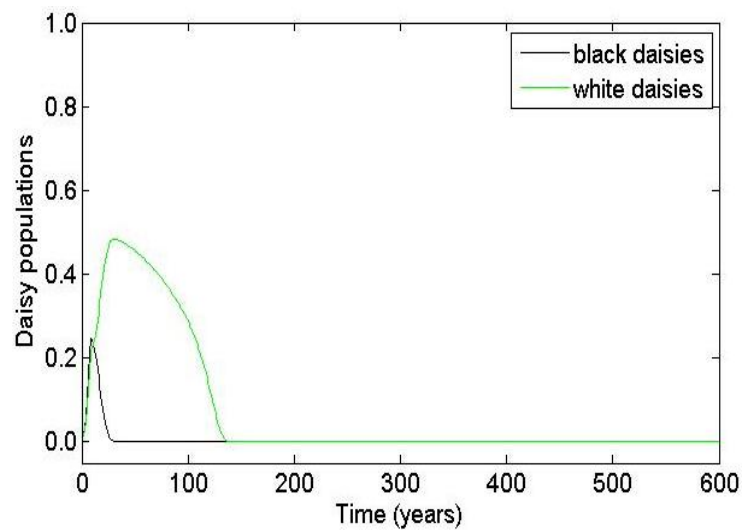

a

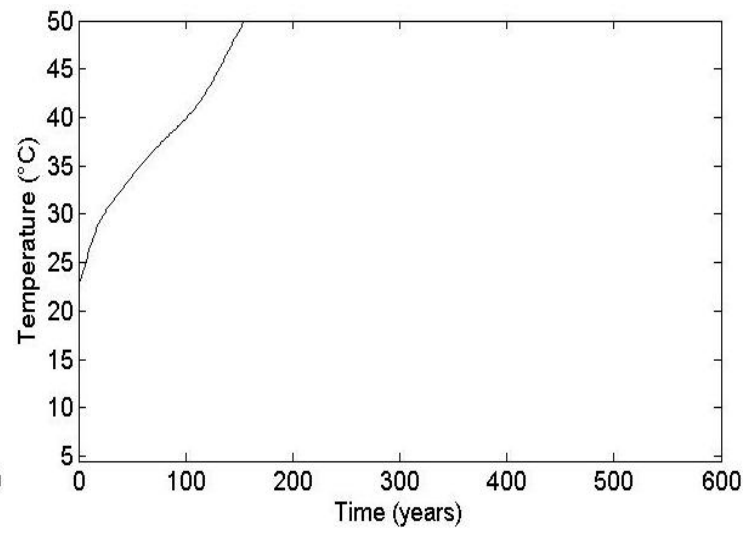

b

Figure 23. Model including organisms for both ice-albedo feedback and greenhouse effect where $f=0.8$ and a sine function variation over a linear increase of $\mathrm{CO}_{2}$. (a) Area fraction of the black and the white daisies; (b) temperature of Daisyworld

The scenarios modelled in this section focused on the impact of ice-albedo feedback and $\mathrm{CO}_{2}$ levels. Two different factors are also incorporated into the model, one representing a planet without organisms and another representing the planet with organisms. The model illustrated that the planet's average temperature gradually rose for all three $\mathrm{CO}_{2}$ mathematical expressions and without the presence of organisms. Each 
model exceeded livable temperatures, making the planet uninhabitable for organisms. The scenario incorporating organisms also resulted in situations where both the black and white daisy species became extinct overtime. Each species attempted to adapt to the average temperature but overtime each was unsuccessful and had eventually died out. When the fraction of land, consisting of both daisy species and bare ground, was decreased in the model the melting of ice area increased. This resulted in the rise of the planet's average temperature. Ultimately resulting in the extinction of both species. The two mathematical expressions of $\mathrm{CO}_{2}$ levels having the greatest impact on rising average temperatures and species extinction were linear increase and sine function over linear increase.

The comparison of all three scenarios in case of with and without the daisies is presented. Under the model without the daisies, the results of a scenarios with icealbedo feedback; and a combination of ice-albedo feedback and $\mathrm{CO}_{2}$ levels illustrate that the average temperature overtime becomes very high compared with a scenario of $\mathrm{CO}_{2}$ levels. All three scenarios, exceeding the point at which the daisies would survive. Under the model with the daisies, the results of all three scenarios show that there is an imbalance between daisy populations and the environment. When compare the interaction between the planet temperature and fractional area of black and white daisies on the Earth's surface among the three scenarios, the results illustrate that as the Earth's average temperature increases, the daisy species become more vulnerable to extinction when apply a combination of ice-albedo feedback and $\mathrm{CO}_{2}$ levels.

\section{Conclusions}

The Daisyworld model, developed by Nevison et al. (1999), introduces environmental processes and factors impacting daisy populations within a simulated planet. The model can be applied to evaluate the status of the Earth and to illustrate the projection of average global temperatures. This study has focused on the impacts of global warming. The specifically model scenarios based on the impact factors of icealbedo feedback and $\mathrm{CO}_{2}$ levels (greenhouse gas representation) are built. The two factors implemented in this study have been modified from the energy balance equation employed in the Daisyworld model. There are three scenarios describing the trend of average global temperature. Firstly, the ice-albedo feedback excluding and including organisms are modelled. The results indicated that without daisies, the average temperature continuously rose over the simulation duration. While the model with daisies illustrated less of an increase in average temperature. This is due to the fact that white daisy population growth reduces the planet's average temperature. Secondly, a scenario on the effects of $\mathrm{CO}_{2}$ levels based on three mathematical expressions is developed. Under constant $\mathrm{CO}_{2}$ levels without organisms, the average temperature reached a steady state, lower than the ice-albedo feedback. $\mathrm{CO}_{2}$ levels increase the planet's average temperature continuously the other two mathematical expressions. Under the models with daisies and the two expressions linear increase and sine function over a linear increase, the black and white daisy species fluctuated between dominance. The results from these two models illustrates that species type can affect the overall average temperature of the planet. However, it was evident that the species which could adapt to high temperature was the white daisy. The results illustrated that black daisy population were at risk of extinction due to higher average temperatures for linear expression and sine over a linear function expression. The final scenario incorporated 
both the ice-albedo feedback and $\mathrm{CO}_{2}$ levels excluding and including organisms. The results illustrated similarities with the second scenario. Under the model without organisms, all three results illustrate that the average temperature overtime becomes very high. Exceeding the point at which organisms would survive. Under the model with organisms, the results illustrate that there is an imbalance between daisy populations and the environment. In all three situations the daisy species eventually become extinct from the increase in average temperature. The key factor for indicating rise in average global temperature for this study was the ice-albedo feedback. As the fraction of land decreases the ice melting area increases. The combination of both icealbedo feedback and $\mathrm{CO}_{2}$ levels have shown to increase the average global temperature. The results have illustrated factors which affect the rise in average global temperatures under the application of the Daisyworld model. The correspondence between the results of this study and situations of the world is driven firstly by the increasing of the amount of $\mathrm{CO}_{2}$ in the atmosphere. As a result, the average temperature increases continuously. Secondly, the rise in the temperature is accelerated by the ice-albedo feedback. However, only two global warming factors which are ice-albedo feedback and $\mathrm{CO}_{2}$ levels are considered in this study. Various factors such as water vapor, $\mathrm{CH}_{4}, \mathrm{~N}_{2} \mathrm{O}$, $\mathrm{CFCs}$ and $\mathrm{SF}_{6}$ should be investigated in future study. Moreover, further experiment cases should be performed on how the Daisyworld model responds to other species of the daisies.

Acknowledgements. The authors thank the Department of Mathematics, Faculty of Science, King Mongkut's University of Technology Thonburi for grant and the research facilities.

\section{REFERENCES}

[1] Ackland, G. J., Clark, M. A., Lenton, T. M. (2003): Catastrophic desert formation in Daisyworld. - Journal of Theoretical Biology 223: 39-44.

[2] Adams, B., Carr, J., Lenton, T. M., White, A. (2003): One-dimensional Daisyworld: Spatial interactions and pattern formation. - Journal of Theoretical Biology 223: 505-513.

[3] Alberti, T., Primavera, L., Vecchio, A., Lepreti, F., Carbone, V. (2015): Spatial interactions in a modified Daisyworld model: Heat diffusivity and greenhouse effects. Physical Review E 92: 052717(1)-052717(11).

[4] Barnsley, M. J. (2007): Environmental Modeling: A Practical Introduction, $1^{\text {st }}$ ed., pp. 251-286. - Taylor \& Francis, Boca Raton.

[5] Biton, E., Gildor, H. (2012): The seasonal effect in one-dimensional Daisyworld. Journal of Theoretical Biology 314: 145-156.

[6] Boyle, R. A., Lenton, T. M., Watson, A. J. (2011): Symbiotic physiology promotes homeostasis in Daisyworld. - Journal of Theoretical Biology 274: 170-182.

[7] Bryson, R. A., Dittberner, G. J. (1976): A non-equilibrium model of hemispheric mean surface temperature. - Journal of the Atmospheric Sciences 33: 2094-2106.

[8] Cohen, J. E., Rich, A. D. (2000): Interspecific competition affects temperature stability in Daisyworld. - Tellus 52B: 980-984.

[9] Dyke, J. G. (2008): Entropy production in an energy balance Daisyworld model. Artificial Life XI: 189-196.

[10] Fraedrich, K. (1979): Catastrophes and resilience of a zero-dimensional climate system with ice-albedo and greenhouse feedback. - Quart. J. R. Met. Soc. 105: 147-167. 
[11] Jones, N. (2017): How the world passed a carbon threshold and why it matters. https://e360.yale.edu/features/how-the-world-passed-a-carbon-threshold-400ppm-andwhy-it-matters.

[12] Kahn, B. (2017): Carbon dioxide is rising at record rates. - http://www.climatecentral.org /news/carbon-dioxide-record-rates-21242.

[13] Lenton, T. M., Lovelock, J. E. (2000): Daisyworld is Darwinian: Constraints on adaptation are important for planetary self-regulation. - Journal of Theoretical Biology 206: 109-114.

[14] Mcgehee, R., Widiasih, E. (2012): A simplification of Budyko's ice-albedo feedback model. - http://www.math.umn.edu/.../McGeheeWidiasihPreprint2012March.pdf.

[15] Nevison, C., Gupta, V., Klinger, L. (1999): Self-sustained temperature oscillations on Daisyworld. - Tellus 51B: 806-814.

[16] NOAA Climate.gov (2017): Climate change: Atmospheric carbon dioxide. https://www.climate.gov/news-features/understanding-climate/climate-changeatmospheric-carbon-dioxide.

[17] Paiva, S. L. D., Savi, M. A., Viola, F. M., Leiroz, A. J. K. (2014): Global warming description using Daisyworld model with greenhouse gases. - Biosystems 125: 1-15.

[18] Punithan, D., Kim, D., Mckay, R. (2012): Spatio-temporal dynamics and quantification of Daisyworld in two-dimensional coupled map lattices. - Ecological Complexity 12: 43-57.

[19] Rueangphankun, T., Sukawat, D., Yomsatieankul, W. (2016a): Interaction between life and environment in a zero-dimensional Daisyworld model. - Proceedings of the $7^{\text {th }}$ RMUTP International Conference on Science, Technology and Innovation for Sustainable Development: Challenges towards the Green Innovative Society, Bangkok, Thailand, pp. 34-37.

[20] Rueangphankun, T., Sukawat, D., Yomsatieankul, W. (2016b): Numerical simulations of global environment using an energy balance Daisyworld model with the variations of solar luminosity. - Proceedings of the $3^{\text {rd }}$ International Conference on Civil, Biological and Environmental Engineering (CBEE-2016), Phuket, Thailand, pp. 125-130.

[21] Salazar, J. F., Poveda, G. (2009): Role of a simplified hydrological cycle and clouds in regulating the climate-biota system of Daisyworld. - Tellus 61B: 483-497.

[22] Saunders, P. T. (1994): Evolution without natural selection: Further implications of the Daisyworld parable. - Journal of Theoretical Biology 166: 365-373.

[23] Svirezhev, Y. M., Von Bloh, W. (1998): A zero-dimensional climate-vegetation model containing global carbon and hydrological cycle. - Ecological Modelling 106: 119-127.

[24] Viola, F. M., Paiva, S. L. D., Savi, M. A. (2010): Analysis of the global warming dynamics from temperature time series. - Ecological Modelling 221: 1964-1978.

[25] Viola, F. M., Savi, M. A., Paiva, S. L. D., Brasil, A. C. P. Jr. (2013): Nonlinear dynamics and chaos of the Daisyworld employed for global warming description. - Applied Ecology and Environmental Research 11(3): 463-490.

[26] Wang, J., Chameides, B. (2005): Global Warming's Increasingly Visible Impacts, $1^{\text {st }}$ ed. pp. 13-22. - Environmental Defense, Los Angeles, USA.

[27] Watson, A. J., Lovelock, J. E. (1983): Biological homeostasis of the global environment: the parable of Daisyworld. - Tellus 35B: 284-289.

[28] Weaver, I. S., Dyke, J. G. (2012): The importance of timescales for the emergence of environmental self-regulation. - Journal of Theoretical Biology 313: 172-180.

[29] Winton, M. (2008): Sea Ice-Albedo Feedback and Nonlinear Arctic Climate Change. In: DeWeaver, E. T., Bitz, C. M., Tremblay, L. B. (eds.) Arctic Sea Ice Decline: Observations, Projections, Mechanisms, and Implications, pp. 111-131. Geophysical Monograph Series 180. American Geophysical Union, Washington, DC.

[30] Zeng, X., Pielke, R. A., Eykholt, R. (1990): Chaos in Daisyworld. - Tellus 42B: 309-318. 